\title{
Neuronal Organization of Fetal Striatal Grafts in Kainate- and Sham- Lesioned Rat Caudate Nucleus: Light- and Electron-Microscopic Observations
}

\author{
Marian DiFiglia, ${ }^{1}$ Leora Schiff, ${ }^{1}$ and A. Wallace Deckel ${ }^{2}$ \\ 'Department of Neurology, Harvard Medical School and Massachusetts General Hospital, Boston, Massachusetts 02114, \\ and ${ }^{2}$ Department of Psychiatry and Mental Health Sciences, University of Medicine and Dentistry of New Jersey, New \\ Jersey Medical School, Newark, New Jersey 07103
}

Behavioral and biochemical studies have suggested that fetal striatal grafts in the adult rat neostriatum can reverse deficits induced by excitotoxic lesions of the host caudate tissue. In this study, fetal day 17-18 striatal grafts were examined at 2, 5-6, 12, and 44-48 weeks following their implantation into saline- or kainic acid-treated host caudate nucleus in order to compare the neuronal organization of the grafts and the host caudate nucleus and to determine whether the differentiation of graft tissue was influenced by the period of implantation or prior lesion of the host caudate nucleus with kainic acid. Compared to host neostriatum, the grafts at the light-microscopic level lacked bundles of myelinated axons and had neurons that were tightly packed in clusters and rich in Nissl substance. Neurons in the grafts were mostly of medium size, had significantly larger crosssectional areas, and more frequently exhibited indented nuclei than host caudate neurons.

At the electron-microscopic level, grafts 2 weeks following implantation contained many features seen in the normally developing neostriatum, such as growth cones, immature synapses, and degenerating profiles. Grafts appeared mature by 5-6 weeks and contained at least 6 types of neurons and 8 types of axon terminals, which formed synapses with cell bodies, dendrites, spines, and axon initial segments. Both symmetric and asymmetric synapses were found within the grafts. The density of synapses was significantly lower in all the transplants than in host tissue, with the exception of the 5-6 week grafts, where values were statistically comparable to host caudate. A significantly higher proportion of axodendritic synapses was present in the graft neuropil than in the caudate nucleus. The lengths of the synaptic junctions in the grafts were the same as those in the neostriatum. There was little qualitative or quantitative difference in synaptic organization between transplants in kainic acid and sham-lesioned host, with grafts in both host treatment conditions exhibiting the same synaptic density and proportion of axodendritic/axospinous synapses.

The development of a highly differentiated ultrastructure within striatal grafts is consistent with recent anatomical

\footnotetext{
Received Dec. 31, 1986; revised Sept. 21, 1987; accepted Sept. 23, 1987.

This work was supported by NIH Grant NS 16367 (M.D.) and the Huntington's Disease Foundation of America (A.W.D.).

Correspondence should be addressed to Dr. DiFiglia, Department of Neurology, Massachusetts General Hospital, Fruit St., Boston, MA 02114.

Copyright (C) 1988 Society for Neuroscience $0270-6474 / 88 / 041112-19 \$ 02.00 / 0$
}

evidence showing interconnections between striatal grafts and host-lesioned caudate nucleus. Although graft neuropil shows striking similarities in neuronal organization to the caudate nucleus, it also exhibits some distinct differences that may have implications for understanding the functional properties of fetal striatal grafts in animal models of Huntington's disease.

Studies in different brain regions have demonstrated that fetal tissue implants can differentiate and establish functional connections in the host brain (Lund and Hauschka, 1976; Björklund et al., 1980; Das et al., 1980; Schmidt et al., 1981; Dunnett et al., 1982; Gage et al., 1983; Gibson et al., 1983). Fetal striatal cell transplants into the neostriatum have been shown to partially reverse the motor deficits (Deckel et al., 1983, 1986a, b, 1987; Isacson et al., 1984, 1986) and biochemical changes (Isacson et al., 1984, 1985) that occur following chemical lesions in the rat caudate nucleus. Anatomical studies have also demonstrated that striatal grafts exhibit Golgi-impregnated neurons characteristic of the neostriatum (McAllister et al., 1985) and form afferent and efferent connections with host tissue (Pritzel et al., 1986). Although light-microscopic observations have provided information about the general histological features of striatal grafts (McGeer et al., 1984; Isacson et al., 1985, 1986; Deckel et al., 1986a), little is known about the synaptic organization of implanted fetal striatal cells that might underlie the functional effects and connectivity with host observed in the studies mentioned above. Since no direct quantitative approaches have been made, the extent to which graft and host striatal tissuc sharc a similar synaptic architecture has been difficult to assess. It is also not known whether the synaptic organization of grafted striatal cells is influenced by the condition of host caudate neurons, i.e., intact or chemically lesioned, prior to implantation.

Anatomical studies were undertaken to examine the development and synaptic organization of fetal striatal implants in sham-lesioned or kainic acid-lesioned ral caudate nucleus, and to compare the organization of the transplants to that of the caudate nucleus. We used the same methods for making lesions and intrastriatal grafts that were used previously by Deckel et al. (1986a) to show the influence of striatal implants on recovery from motor dysfunction induced by kainic acid injections into the rat caudate nucleus. Within the grafts, we looked for qualitative indices of a developing neuropil, such as the maturity and diversity of synaptic contacts, the formation of myelinated 
axons, and the incidence of degenerating profiles. The morphological features in the grafts that were quantified and compared to host caudate nucleus included the size of neuronal perikarya, the frequency of medium-sized neurons with indented nuclei, the density of synapses, frequency of synaptic types (axodendritic and axospinous, symmetric versus asymmetric), and the length of synaptic contacts. These parameters were selected for quantitative measurc bccausc they have been used previously (Pasik et al., 1976; DiFiglia et al., 1979; Graveland and DiFiglia, 1985 ) to describe neostriatal organization. A preliminary report of this work was presented previously (DiFiglia et al., 1985).

\section{Materials and Methods}

\section{Preparation of fetal translants, host animals, and tissue} sections

The protocol used for the preparation of host animals and striatal grafts was the same as that of Deckel et al. (1986a). Sprague-Dawley rats (female; $n=14$ ) were anesthetized with chloropent $\left(0.3 \mathrm{~cm}^{3} / 100 \mathrm{gm}\right.$ body weight) and given bilateral injections in the caudate nucleus of either $0.4 \mu \mathrm{l}$ of PBS (sham-lesion control for nonspecific tissue damage) or kainic acid (0.8 $\mu \mathrm{g}$ kainic acid dissolved in $0.4 \mu \mathrm{l}$ of PBS, $\mathrm{pH} \mathrm{7.4,}$ delivered at the rate of $0.1 \mu \mathrm{l} / 90 \mathrm{sec}$ ). One week following the injections, animals received mechanically dissociated nontrypsinized suspensions $(2.4 \mu \mathrm{l})$ of $17-18 \mathrm{~d}$ fetal striatal tissue at the following stereotaxic coordinates from bregma: A, $1.5 \mathrm{~mm} ; \mathrm{L}, 2.2 \mathrm{~mm}$; and H, $4.5 \mathrm{~mm}$ (from dura). Preparations of the graft tissue involved dissection of the ventricular ridge from the embryonic brain, and trituration (about $5 \times$ ) of the striatal tissue with a glass pipette (bore size, $0.5 \mathrm{~mm}$ ). Each dissected striatum served as tissue for one transplant.

Host animals were killed at $2,5-6,12$, and $44-48$ weeks following the fetal tissue transplant. Separate operating sessions and fetuses from different dams were used in half of the 5-6 week group and in the 4448 week group. Different fetuses from 2 dams were used at random in one operating session to prepare grafts in the 2 week, half of the 5-6 week, and the 12 week groups. Two animals treated with saline and 2 treated with kainic acid served as hosts for each group of grafts aged 2, 5-6 and 12 weeks old. Two animals were hosts for the oldest grafts, which were 48 weeks old (in a saline-treated host) and 44 weeks old (in a kainic acid-treated host). In total, 26 transplants ( 12 in sham-lesioned and 14 in kainate-lesioned hosts) from 14 animals (see Table 1 for the number of grafts examined for each age/treatment condition) were examined.

The host rats were deeply anesthetized and perfused through the heart with $500 \mathrm{ml}$ of a fixative containing $1-2 \%$ paraformaldehyde and $1 \%$ glutaraldehyde in $0.15 \mathrm{~m}$ phosphate buffer at $\mathrm{pH} 7.3$. The brain was left in the skull overnight in fixative at $4^{\circ} \mathrm{C}$ and removed the following day. The brain region containing the caudate nucleus was blocked in the coronal plane, and 50- $\mu \mathrm{m}$-thick sections were cut through the caudate nucleus with a Vibratome. Alternate sections were set aside for light- and electron-microscopic study. Tissue sections for light microscopy were mounted on subbed slides and stained with the KluverBarrera method (1953). Sections for electron microscopy were postfixed in $1 \%$ osmium tetroxide for $1.5 \mathrm{hr}$, stained en bloc with $1 \%$ uranyl acetate for $2 \mathrm{hr}$, and embedded in Epon between 2 sheets of Aclar. The flat-embedded sections were viewed in the light microscope, and, at the $\Lambda-P$ level exhibiting the maximum growth of the transplanted tissue, small areas from the center of the graft and from the host caudate nucleus at least $1 \mathrm{~mm}$ away from the graft (saline-treated group only) were cut out and mounted on blank Epon blocks. The boundary between transplant and host was easily recognized in the osmium-treated plasticembedded sections (see Results; Fig. 4, $a, b)$. Semithick sections $(1 \mu \mathrm{m}$ ) were cut and mounted in series and stained with toluidine blue. Ultrathin sections were cut, mounted on Formvar-coated slot grids, stained with lead citrate, and examined in a Jeol $100 \mathrm{CX}$ electron microscope.

\section{Quantitative methods used to study transplants and host caudate nucleus}

Cross-sectional area of the implants. The Kluver-Barrera-stained sections were viewed with an overhead microprojector (Tri-simplex), and the area of the transplant and surrounding caudate nucleus was drawn at $18.7 \times$. The cross-sectional area of that portion of the graft falling within the boundaries of the neostriatum was measured from the drawings, using a digitizer (Graf-pen). The A-P level with the maximum cross-sectional area of each graft was determined by matching the stained sections with drawings from a rat stereotaxic atlas (Pelligrino et al., 1979).

Size and frequency of cell types. Semithick sections of tissue that was selected from at least 2 grafts per age/treatment group were examined under $100 \times$ oil immersion; all cells of medium size that contained a recognizable nucleolus were classified as having either an indented or unindented nucleus. Large neurons (longest axis $>25 \mu \mathrm{m}$ ) with a nucleolus present were also recorded. The slides were marked solely with code numbers, permitting the classification to be performed blind by one of us. A total of 7741 neurons were examined in the implants, and 2336 neurons in the host caudate tissue. A field was then selected at random and the contours of all neurons with medium-sized neuronal perikarya (10-24 $\mu \mathrm{m}$ in their longest dimension on the eyepiece reticule) were traced at $1620 \times$ using a drawing tube. The cross-sectional areas were determined using a digitizer. A total of 391 cells were examined in the implants and 130 neurons in host caudate tissue. Measurements of neuronal size were analyzed statistically using a 2-way analysis of variance (ANOVA), followed by the Newman-Keuls test for multiple comparisons of means (Zar, 1974)

Synaptic density, synaptic length, and frequency of synaptic types. Random photographs of graft and host neuropil were taken at 13,000× (11-30 micrographs per transplant). A minimum of 2 grafts per age/ treatment were used in the analysis. Prints were made at a final magnification of $32,500 \times$. The specific usable area of each micrograph was measured (portions of cell bodies and large glial masses were deleted from the overall area). The total number of synapses in a given micrograph was then divided by the area of the micrograph, and values were normalized and expressed as the number of synapses $/ 100 \mu \mathrm{m}^{2}$. A total of 7935 synapses were counted in the implants and 3282 in host caudate nucleus. Synapses were classified with respect to the following parameters: axospinous or axodendritic, symmetric or asymmetric. In order for a synapse to be counted in the tally, pre- and postsynaptic membrane thickenings, as well as vesicles near or touching the presynaptic membrane, had to be evident. Asymmetric synapses had postsynaptic membrane densities that were thicker than the presynaptic densities, whereas in the symmetric synapses, the membrane thicknesses were equal. All classifications were performed blind, the numbers on the micrographs being matched to their source only after the micrographs had been marked. The number of synapses within each category and the total number of synapses were tallied for each implant and host caudate. The lengths of synaptic junctions were measured using a digitizer. Synapses that were partially cut off or whose membrane limits were unclear were excluded from the total.

Statistical analysis. Throughout the study, each of the 2 implants from a given animal was treated independently. Grafts were grouped according to agc and treatment (sce Table 1 for the number of implants per group); samples of host caudate tissue were selected from 7 shamlesion hosts and pooled to form a single group. All quantitative data (except cross-sectional areas of neurons) were analyzed by a computer program, Statistical Analysis System (SAS Institute, Cary, NC). First, a 2-way ANOVA was used to determine whether age, treatment (saline or kainic acid lesion), or age/treatment interactions were present. If neither a treatment nor an interaction effect was evident, the data were then pooled within each age group and a 1-way ANOVA was performed comparing data from the different-aged implants to the host group. If either the 2-or the 1-way ANOVA showed a significant effect, Duncan's Multiple Range Test was performed in order to determine which pairs of means were significantly different.

\section{Results}

\section{General histological features of the grafts}

Examples of the grafts examined in this study are illustrated schematically in Figure 1, which shows the largest and smallest grafts for each age/treatment condition and A-P level of maximum cross-sectional area. The coronal level in which a given implant exhibited its maximum cross-sectional area ranged from 2.2 to $4.0 \mathrm{~mm}$ anterior to bregma. Considerable variation existed in the overall size of the grafts, with individual values ranging from 0.5 to $3.7 \mathrm{~mm}^{2}$ in cross-sectional area. The mean values of the maximum cross-sectional areas of the implants at 

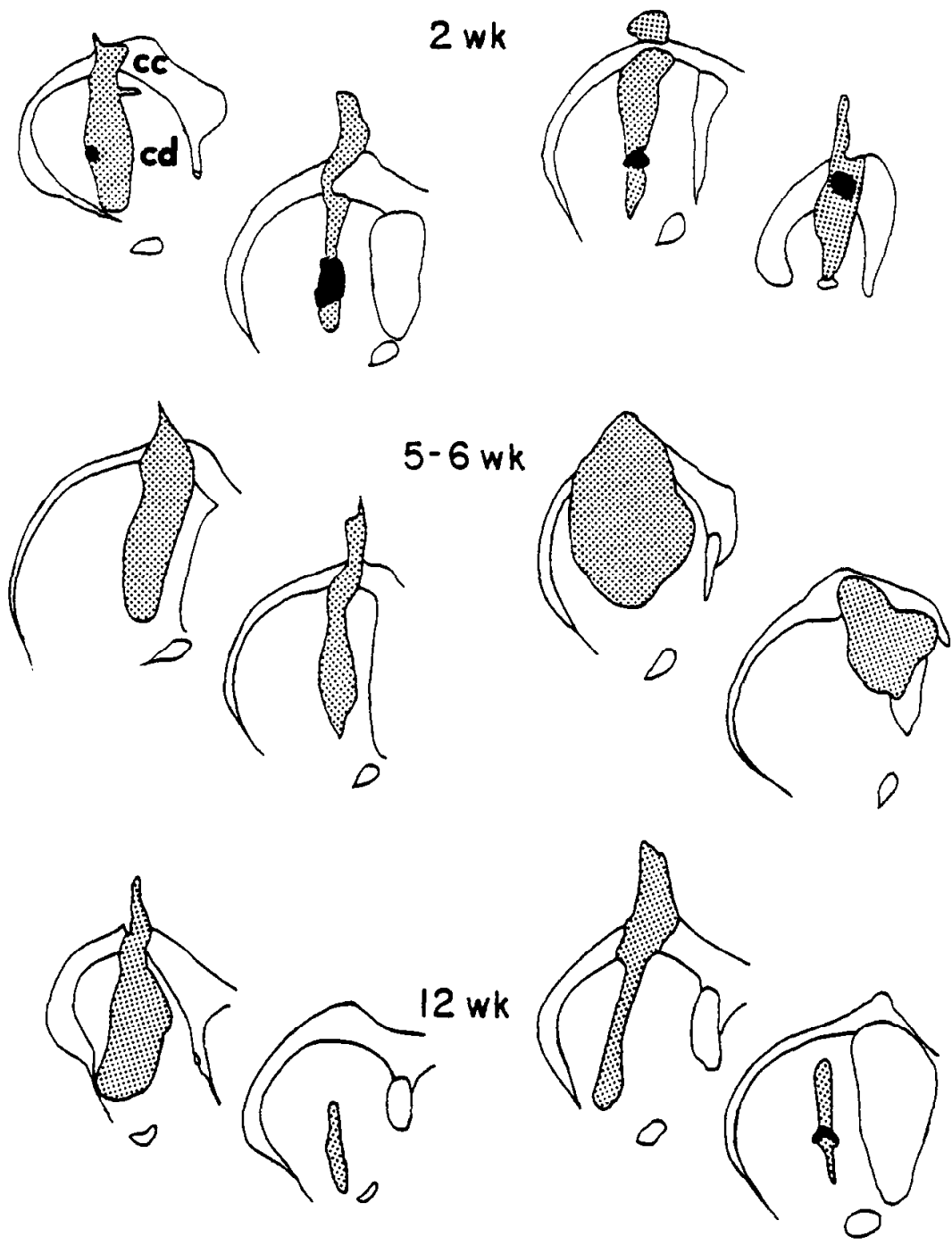

Figure 1. Drawings made from Nisslstained coronal sections show the extent of the fetal striatal implants (shaded areas) at 2, 5-6, 12, and 44-48 weeks for the 2 treatment conditions. For each age/treatment, the implant at the upper left was the largest and the one at the lower right the smallest in cross-sectional area of those implants examined in this study. Solid black areas are necrotic zones deleted from the calculations of cross-sectional area. Note that the majority of the implants extend into the cerebral cortex. $c d$, Caudate nucleus, $c c$, corpus callosum. Scale bar, $3 \mathrm{~mm}$.
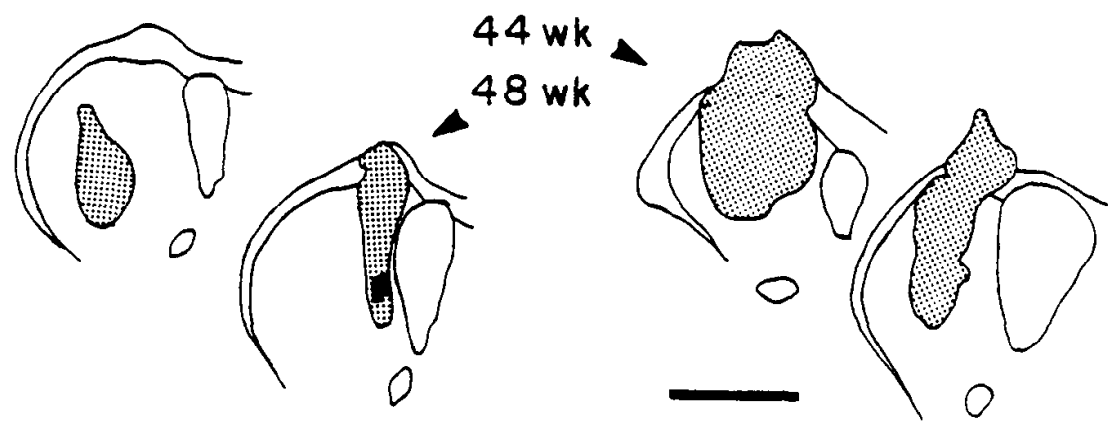

each age and pretreatment condition are presented in Table 1. Implants also differed in their morphology, exhibiting a variety of irregular contours. Despite this diversity, however, the implants showed their greatest growth along the dorsoventral axis (Fig. 2a). The majority of the grafts also displaced the overlying cerebral cortex (Fig. 2b).

Grafted cells were frequently organized into clusters composed of larger or smaller cells (Figs. $2 ; 3, a-c$ ) and showed more intense Nissl staining than host caudate neurons (Fig. 3, b, c). Although usually more extensive in the kainic acid-lesioned rats, glial cells were visible along the boundaries with host caudate in most of the grafts (Figs. 2, $a, b ; 3 b$ ). In one case, in which a glial cell border was not prominent at the light-microscopic level, a glial cell interface between the transplant and host caudate was seen at the electron-microscopic level. In the osmiumtreated, plastic-embedded sections used for electron-micro- 

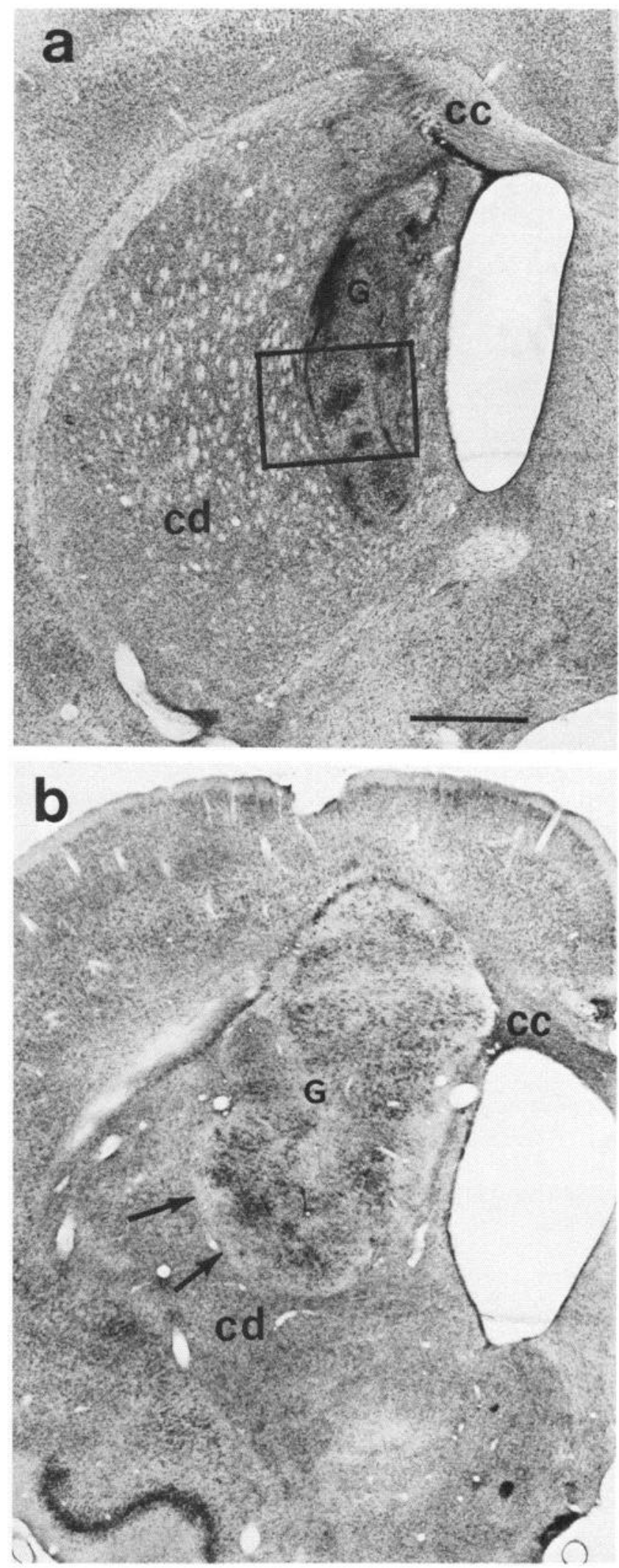

Figure 2. Kluver-Barrera-stained coronal sections of the rat brain at $6(a)$ and $44(b)$ weeks following injection of fetal striatal cells into the anterior neostriatum. Graft tissue $(G)$ can be readily distinguished from host by its histological appearance. Host caudate nucleus in $a$ was treated with saline, and in $b$ with kainic acid. Note that the transplant in $b$ has expanded dorsally and compressed the corpus callosum. Area in square scopic study (Fig. 4, $a, b$ ) the implant zone had a paler appearance relative to host caudate because the grafts lacked the bundles of myelinated fibers found in the neostriatum. Some myelinated fibers were present within the transplant (see below for development of myelinated fibers); at levels where transplants extended dorsally through the corpus callosum and into cortex, myelinated fibers from the cortex appeared to extend ventrally and to traverse the implant zone for long distances (Fig. $4 b$ ).

Size and frequency of neuronal populations. As in the neostriatum, the majority of neurons in the grafts were of medium size, as determined from measures of their longest somatic axes $(10-24 \mu \mathrm{m})$. Medium-sized neurons in the grafts nevertheless appeared somewhat larger than host caudate cells, and in all age/treatment conditions their mean cross-sectional areas were significantly larger $\left(\bar{X}\right.$ s ranged from $172.4 \pm 10.9 \mu \mathrm{m}^{2}$ for the 2 week/kainic acid group to $239.1 \pm 31.6 \mu \mathrm{m}^{2}$ for the 48 week sham; Newman-Keuls test: $p<0.01$ ) than those of host neurons $\left(\bar{X}=141.8 \mu \mathrm{m}^{2} \pm 8.5\right)$.

The incidence of medium-sized neurons with indented nuclei (Fig. 5) was the same in both host treatment conditions, but increased significantly with the age of the graft (2-way ANOVA: $F(3,18)=6.95, p<0.01)$ such that mean values were significantly different between 2,12 , and 44-48 weeks postimplantation (Duncan's Multiple Range Test: $p<0.05$ ). The proportion of neurons with indented nuclei was significantly larger (1way ANOVA: $F(4,28)=13.41, p<0.0001$; Duncan's Multiple Range Test: $p<0.05$ ) in all of the implants (means ranged from 17 to $69 \%$ ) than in host tissue (mean, $5 \%$ ).

The frequency of large neurons $(>25 \mu \mathrm{m}$ in their longest somatic axis) (Fig. 6) varied considerably, with mean values in individual grafts ranging from $0 \%$ ( 2 weeks/sham) to $12 \%(12$ and 48 weeks/sham). Statistical analysis showed that the proportion of large neurons was not significantly affected by host treatment and was significantly influenced by the age of the graft (2-way ANOVA: $F(3,18)=3.28, p<0.05)$. The oldest implants (44-48 weeks) had a significantly higher frequency of large neurons than the 2 and 5-6-week-old implants (Duncan's Multiple Range Test: $p<0.05$ ). The proportion of large cells in the 2 and 5-6-week-old grafts was comparable to host levels and was significantly higher (1-way ANOVA: $F(4,28)=2.95, p<0.05$; Duncan's Multiple Range Test: $p<0.05$ ) in the 12 (means, $4.4 \% /$ sham and $2.4 \% /$ kainate) and $44-48$ week implants (means, $7.6 \% /$ sham and $1.3 \% /$ kainate) than in host caudate (mean, $0.9 \%$ ).

\section{Electron-microscopic observations}

Tissue from 24 grafts was examined at the ultrastructural level. Qualitative differences in neuronal development and organization of fetal implants grown in saline-pretreated or kainatelesioned caudate nucleus were not discernible. Therefore, the following descriptions apply to implants grown under both host treatment conditions.

Neurons. At least 6 types of neurons were observed within the grafts 6-12 weeks postimplant (Fig. 7). Small neurons (less than $10 \mu \mathrm{m}$ ) were frequently observed among clusters of glial cells. They contained many chromatin aggregates within and at

in $a$ is shown at higher magnification in Figure $3 a$, and arrows in $b$ identify border zone between host and transplant shown in Figure $3 b$. $c d$, Caudate nucleus, $c c$, corpus callosum. Scale bar, $1 \mathrm{~mm}$ for $a$ and $b$. 


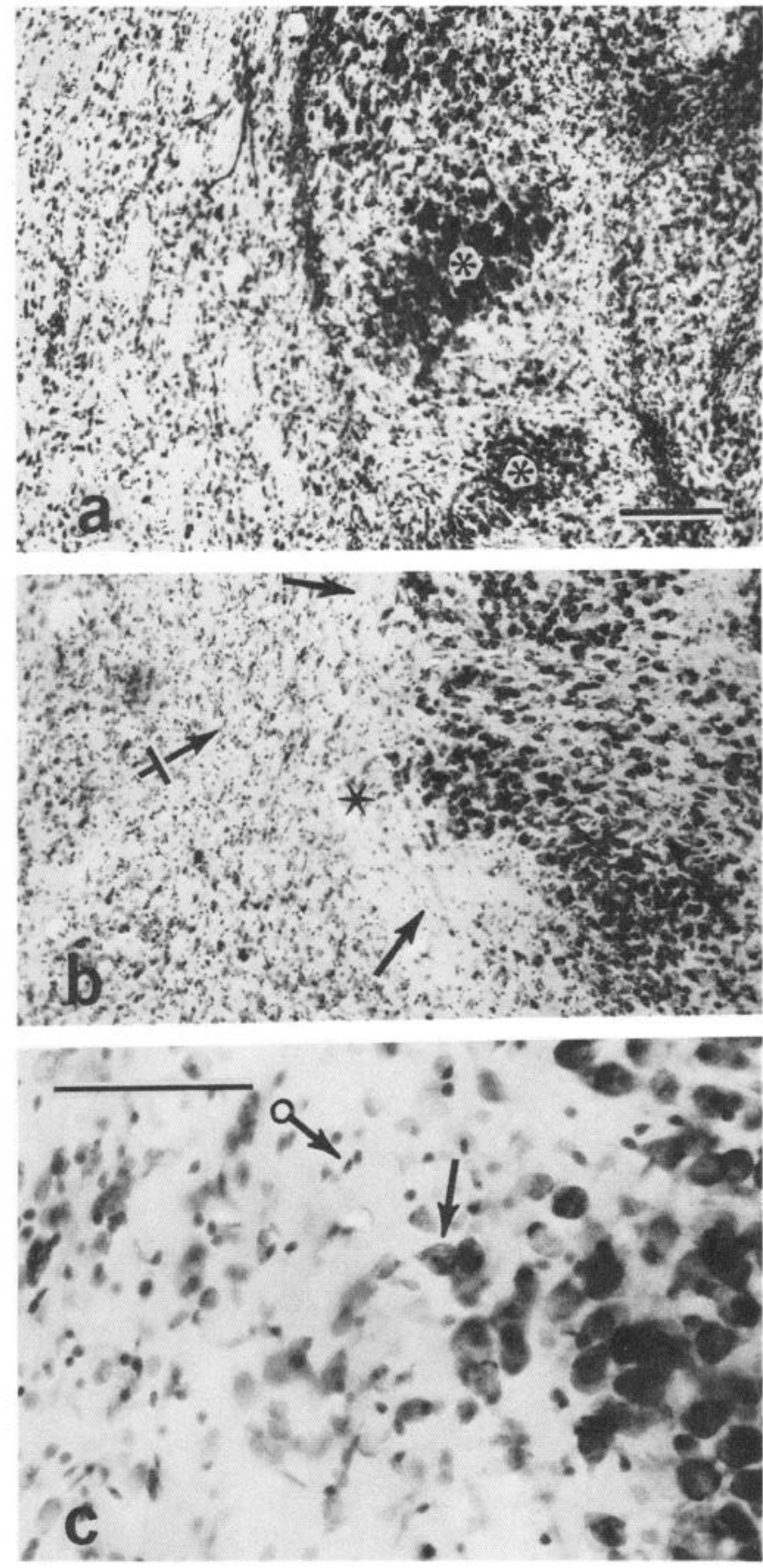

Figure 3. Border zones between transplants (right side of each photograph) and host tissue (left side of each photograph) show differences in cytoarchitecture between graft and host. $a$, Taken from squared region in Figure $2 a$. $b$, Taken from region between arrows in Figure $2 b$. Note in $a$ and $b$ the clusters (asterisks in $a$ ) of darkly stained cells and the relatively large size and dense packing of neurons in the transplant zone. The pale areas adjacent to graft (arrows in $b$ ) contain mostly glial cells. The extended area of low cell density and increased gliosis within host tissue (crossed arrow in $b$ ) is due to the effects of kainic acid. Scale bar, $200 \mu \mathrm{m}$ for $a$ and $b$. $c$. Area indicated by the asterisk in $b$, showing large, darkly stained neurons (arrow) in the transplant, and nuclei of glial cells in the border zone (ringed arrow). Scale bar, $100 \mu \mathrm{m}$.

the borders of their nuclei and a very thin rim of cytoplasm, which was sparsely filled with organelles. The small cells were postsynaptic to axon terminals. Three types of medium-sized neurons were found; they included neurons with unindented nuclei and a relatively sparse content of organelles (Fig. $7 b$ ), neurons with indented nuclei and a relatively abundant proportion of cytoplasmic organelles (Fig. $7 c$ ), and cells with unindented nuclei and numerous organelles, including Nissl bodies within the cytoplasm. There were 2 types of large neurons ( $>25$ $\mu \mathrm{m}$ ). One type (Fig. $7 a$ ) was globular, had a markedly indented nucleus and an abundance of rough endoplasmic reticulum within its cytoplasm. The other type (Fig. 7d) exhibited an elongated shape and a large, slightly indented nucleus. All types of medium-sized and large neurons received synaptic inputs to their cell bodies.

Degeneration within the grafts. Degeneration in the form of electron-dense profiles was seen in the transplants grown in sham- or kainate-lesioned caudate at 2, 5-6, and 12 weeks after implantation (Fig. 8, $a-c$ ). Different forms of dark degeneration were observed. Small, darkened profiles engulfed in glia were observed frequently (Fig. $8 a$ ). They were not, however, clearly recognizable as neuronal structures. Dark, degenerating axon terminals (Fig. 8c) were also seen. Regions of the implant with heavy gliosis also contained dark profiles that were usually larger in size (up to $4 \mu \mathrm{m}$ ) and may have originated from cell bodies (Fig. $8 b$ ).

Development and organization of myelin. Between 2 and 12 weeks postimplant there was an increase in the number of lamellae of myelin-ensheathing axons, in the overall number of myelinated axons present within the neuropil and in the overall size of fiber bundles composed of myelinated axons (Fig. 8, $d-$ $f$ ). At 2 weeks postimplant, only immature (Fig. $8 d$ ) or thinly myelinated (Fig. $8 e$ ) fibers could be found sparsely distributed throughout the transplants. By 6 weeks individual myelinated fibers appeared throughout the implant neuropil and were also organized into small bundles. Some of the myelinated axons in 6 week transplants and older grafts gave rise to terminal or en passant swellings that contained round vesicles and formed asymmetric synapses with dendrites and spines (Fig. 12, $a, b$ ). By 12 weeks, both thinly and thickly myelinated fibers $0.5-1.5$ $\mu \mathrm{m}$ in diameter were present throughout the implant neuropil and were organized into larger bundles (Fig. 8f).

Two-week-graft neuropil. At 2 weeks postimplant there was considerable evidence of immaturity and active growth within the grafts. The neuropil (Fig. 9) contained many pale, vacuolefilled profiles, axon terminals with relatively few vesicles (Fig. $9 a$ ), and relatively large extracellular spaces (Fig. 9d). Dendritic growth cones were observed and numerous polyribosomes were found within both large and small dendrites (Fig. 9b). Most of the axon types were not easily categorized at this stage and appeared fewer in number than in the older implants. The frequency of contact sites (accumulation of dense material) between neuronal profiles appeared low relative to that of the older grafts. Many of the junctions were immature because relatively few or no vesicles appeared presynaptically at contact zones. Dendrites with spines (Fig. $9 b$ ) and smooth-surfaced varicose dendrites (Fig. 9d) were present and received a sparse input of mature synapses of both symmetric and asymmetric types. In some locations within the neuropil, clusters of 4-5 synapses formed by small neuronal profiles were observed (Fig. 9c). Few mature synapses onto cell bodies were found, and those present involved mostly medium-sized neurons with indented nuclei.

Five-six-week-implant neuropil. A striking change in the appearance of the neuropil occurred between 2 and 5-6 weeks postimplantation (Fig. 10). At 5-6 weeks, numerous spiny dendrites (Fig. 10a) and smooth dendrites of large diameter (Fig. 

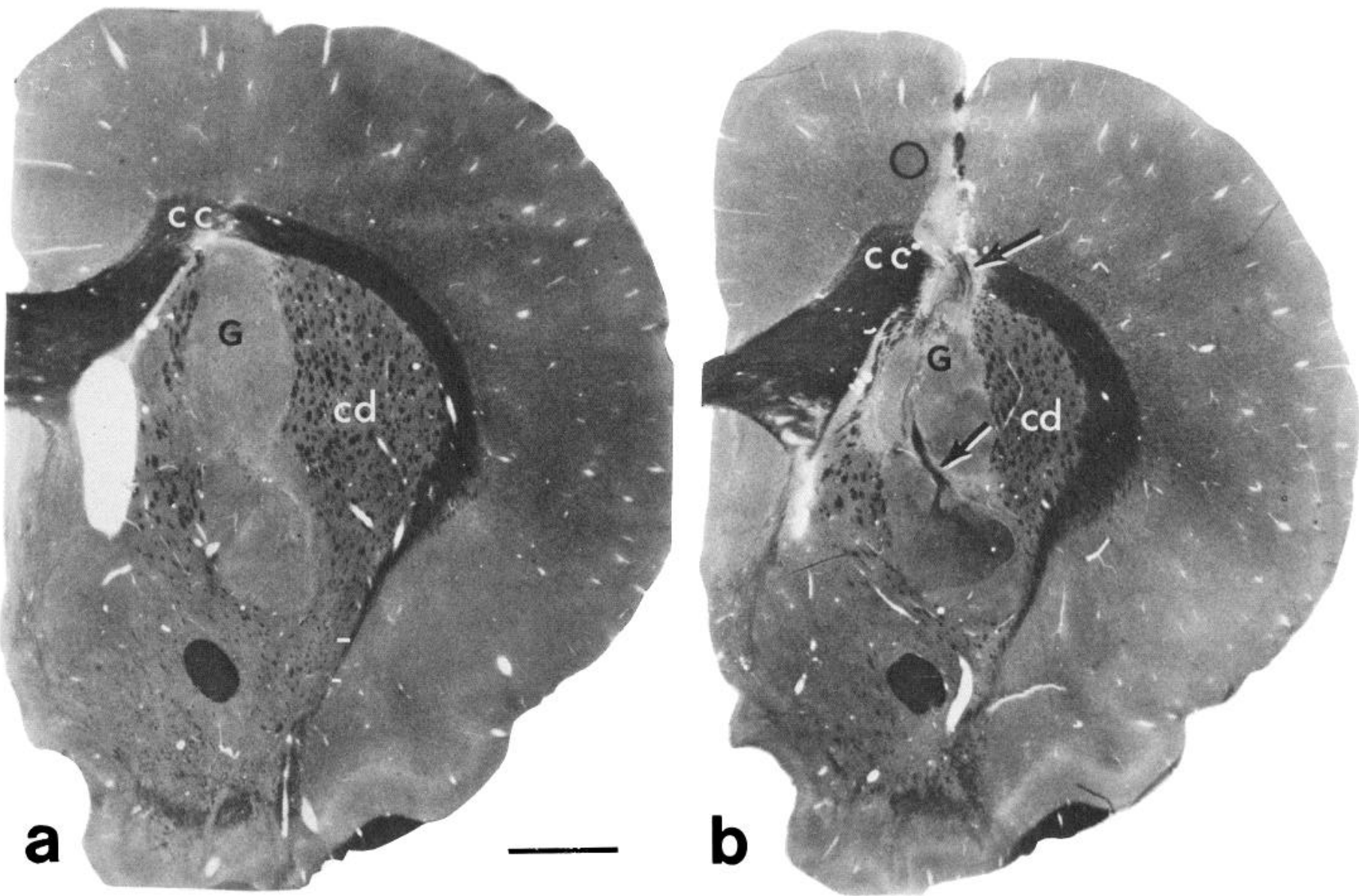

Figure 4. Osmium-treated, plastic-embedded sections from a 6-week-old graft in a sham-lesioned host caudate nucleus. $a$, Graft $(G)$ is clearly distinguished from host by its paler staining and the absence of myelinated axons that stain black and form bundles distributed throughout the host caudate nucleus $(c d)$. $b$, Graft extends through the corpus callosum $(c c)$ into the cortex. A band of myelinated fibers (arrows) courses through the transplant and may originate from the cortex or corpus callosum. Scale bar, $1 \mathrm{~mm}$.

$10 b$ ) were found throughout the neuropil. Axonal boutons were filled with vesicles and different types of axon terminals were easily recognized. Contacts between neuronal profiles were more frequent and most appeared to be mature synapses. Synapses onto most types of cell bodies were seen, and some somata received a high density of synaptic inputs. Two patterns of synaptic organization emerged in the neuropil of the 5-6 week striatal transplants. The first and predominant synaptic pattern consisted of axon terminals making synaptic contacts with numerous dendritic spines and the shafts of small dendrites (Fig. $10 a$ ). The second and less frequent type of synaptic organization involved the ensheathment of dendrites and spinelike processes by numerous synaptic boutons (Fig. 10, $b, c$ ). The 2 types of synaptic architecture could be found within the same ultrathin section, but usually in separate regions of the neuropil rather than intermixed.

Twelve week and 44-48 week implants. The 2 patterns of synaptic organization that began to emerge in the 5-6 week grafts also appeared in the 12 week and older (44-48 week) transplants. The more predominant pattern was characterized by numerous synapses onto the spines and shafts of small dendrites (Fig. 12a). The less frequent pattern was the ensheathment of large and small dendrites by numerous synapsing boutons (Fig. 12b).

Types of synapses and bouton types present within the implant. In the 6 and 12 week implants, a surprising variety of synaptic interactions and bouton types became established (Figs. 10, 12,

Table 1. Maximal cross-sectional area of striatal transplants (mean in $\mathbf{m m}^{2} \pm$ SD)

\begin{tabular}{lllll} 
& 2 week & $5-6$ week & 12 week & $44-48$ week \\
\hline Sham lesion & $1.28 \pm 0.55$ & $1.87 \pm 0.60$ & $1.30 \pm 1.15$ & $1.40 \pm 1.15$ \\
& $(n=4)$ & $(n=3)$ & $\begin{array}{l}(n=3) \\
(n=2)\end{array}$ \\
$\begin{array}{c}\text { Kainic acid } \\
\text { lesion }\end{array}$ & $\begin{array}{l}1.13 \pm 0.33 \\
(n=4)\end{array}$ & $\begin{array}{l}3.20 \pm 1.50 \\
(n=4)\end{array}$ & $\begin{array}{l}0.85 \pm 0.26 \\
(n=4)\end{array}$ & $\begin{array}{l}2.85 \pm 0.92 \\
(n=2)\end{array}$ \\
\hline
\end{tabular}

ANOVA with post hoc Duncan's Multiple Range Test showed 5-6 week grafts were significantly larger $(p<0.05)$ than those in other age groups. $n$, Number of grafts. 
Figure 5. Frequency of medium-sized neurons with indented nuclei (expressed as the mean percentage $\pm \mathrm{SD}$ of total medium-sized neurons) in the grafts at different ages and treatments (saline or kainic acid, $K A$ ) and in the host caudate nucleus $(n=7)$. The number of grafts examined for each age/ treatment is the same as in Table 1. ANOVA with post hoc Duncan's Multiple Range Test showed 2, 12, and 4448 week groups to be different from one another at $p<0.05$, and all age groups to be different from host at $p<0.05$.

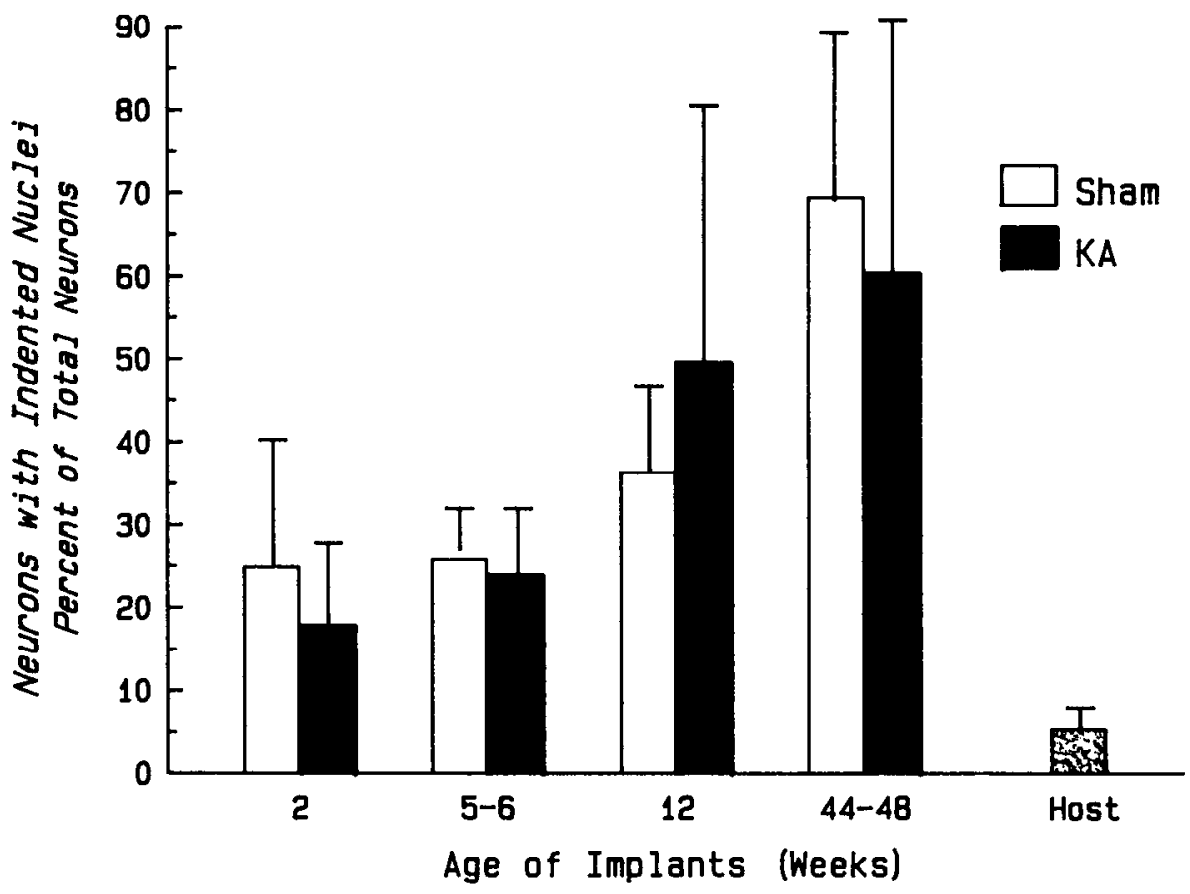

neuropil of the grafts. The most frequent type of axon that formed an asymmetric synapse with spines and dendritic shafts (Figs. $10, a-c ; 12, a, b)$ was small to medium in size $(0.5-1 \mu \mathrm{m})$ and contained round vesicles that filled most of the surface area of the bouton. These boutons arose from myelinated axons (Fig. $12, a, b)$. Two other bouton types that formed asymmetric synapses were often associated with prominent postsynaptic dense bodies and included medium-sized $(1 \mu \mathrm{m})$ vesicle-filled boutons (Fig. 12c) and large boutons (2-3 $\mu \mathrm{m}$ ) that were sparsely filled with vesicles (Fig. 12d). Axon terminals forming symmetric membrane densities included small boutons $(0.5 \mu \mathrm{m})$ densely filled with highly pleomorphic vesicles (Fig. 13a), small boutons
Figure 6. Frequency of large neurons expressed as a mean percentage of total neurons sampled for each age/treatment and in host caudate nucleus $(n=$ 7). The number of grafts examined for each age/treatment is the same as in Table 1 . Mean for 2 weeks $/$ sham $=0 \%$. ANOVA with post hoc Duncan's Multiple Range Test showed 44-48 week group different from 2 and 5-6 week implants with $p<0.05$ and 12 and 44 48 week grafts different from host at $p<0.05$.

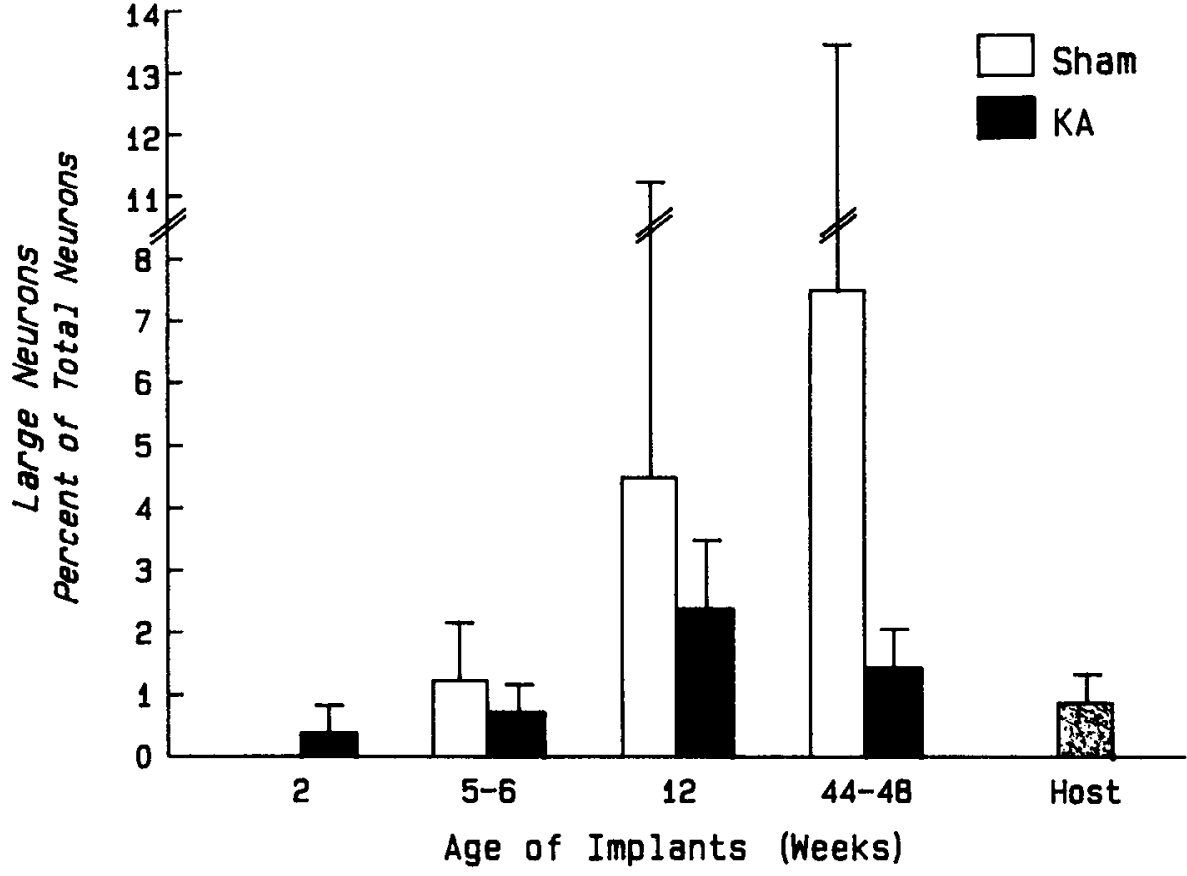




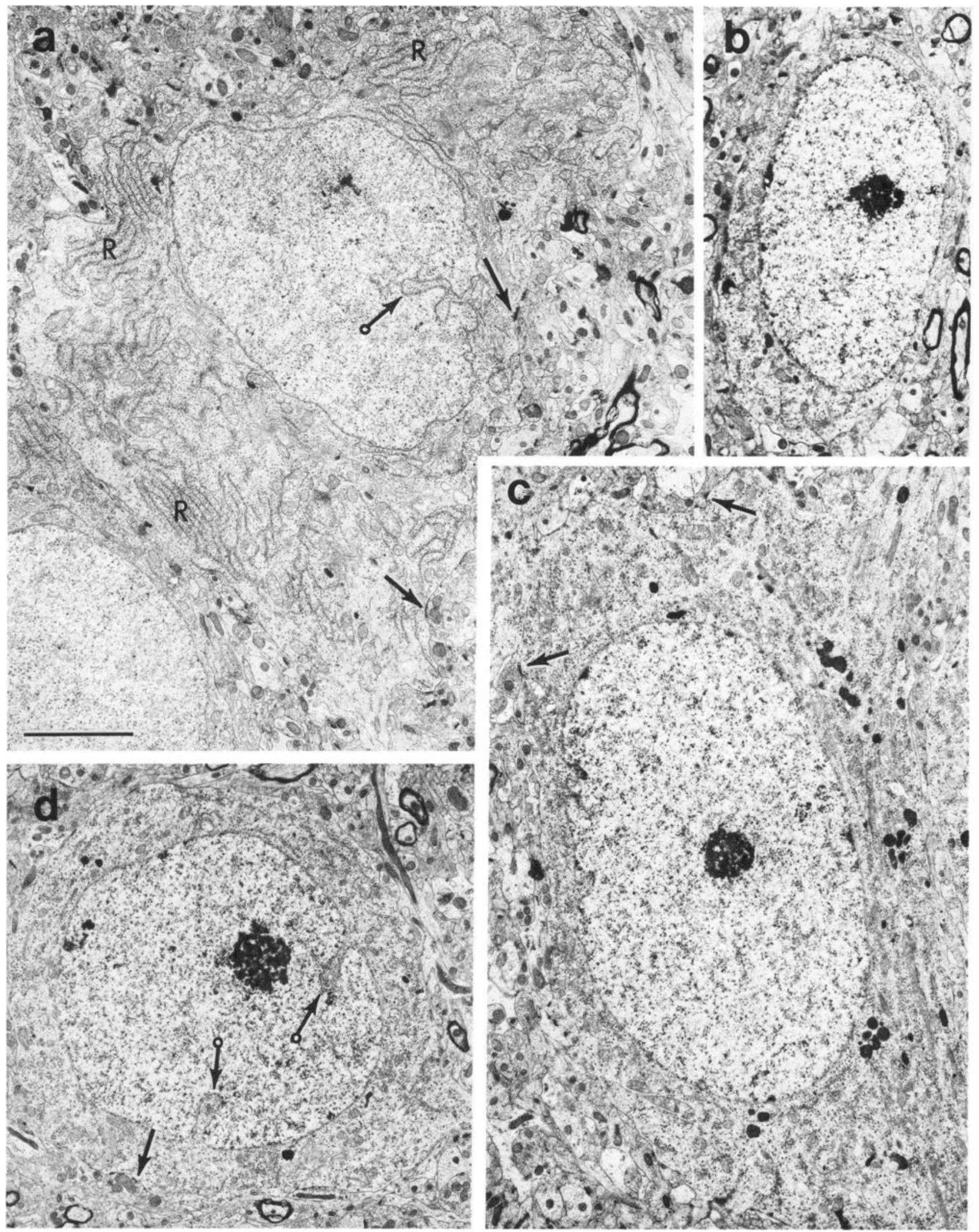

Figure 7. Neuronal types within striatal transplants. $a$, Large neuron from a 6 week transplant in sham-lesioned host has a pale, invaginated nucleus and a cytoplasm with abundant rough endoplasmic reticulum $(R)$. Neuron is postsynaptic at numerous sites (arrows). $b$, Medium-sized neuron from a 12 week transplant in a sham-lesioned host has an unindented nucleus and little cytoplasm, which contains relatively few organelles. $c$, A large neuron from a 48 week transplant in sham-lesioned host, with fusiform shape and an elongated nucleus. Neuron is postsynaptic at arrows. $d$, Medium-sized neuron from a 44 week transplant in kainate-lesioned caudate nucleus exhibits an indented nucleus (ringed arrows). The cytoplasm has a greater density of organelles than does the medium-sized neuron shown in $b$. The cell is also postsynaptic at arrow. Scale bar, $4 \mu \mathrm{m}(a-d)$. 

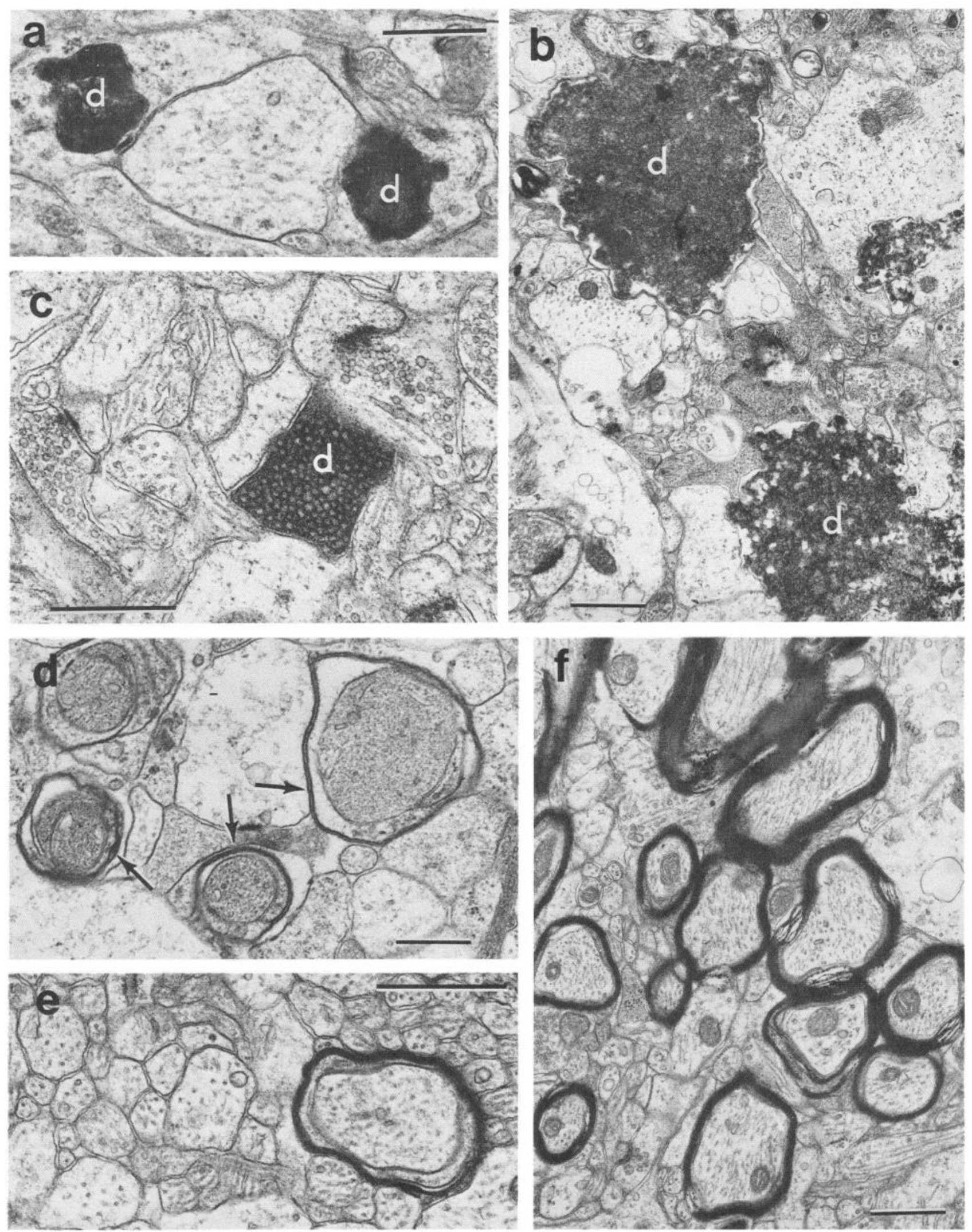

Figure 8. Degenerating profiles $(a-c)$ and the formation of myelinated axons $(d-f)$ in the grafts. $a$, Darkened, degenerated profiles $(d)$ are encapsulated by glia. Taken from a 2 week transplant in sham-lesioned neostriatum. $b$, Large, degenerating profiles $(d)$, probably originating from cell bodies or primary processes, are surrounded by glia in this region of a 12 week transplant in sham-lesioned neostriatum. Note the axospinous synapse at lower left. c, A dark-stage degenerating axon $(d)$ is near 2 normal axons forming synapses with spines in a 6 week graft in a sham-lesioned caudate nucleus. $d$, Formation of myelin (arrows) is evident in this group of axons found in a 2 week implant in a kainate-lesioned caudate nucleus. $e$, A thinly myelinated axon appears within a bundle of small, unmyelinated axons in a 2 week transplant in a sham-lesioned host neostriatum. $f$, A bundle of small- and large-diameter myelinated axons found in a 12 week transplant in a sham-lesioned host caudate nucleus. The number of lamellae of myelin (arrows) is greater than that in the axons of the 2 week grafts (compare to $d$ and $e$ ). Scale bars: $a, b, d-f, 0.5 \mu \mathrm{m} ; c, 1 \mu \mathrm{m}$. 

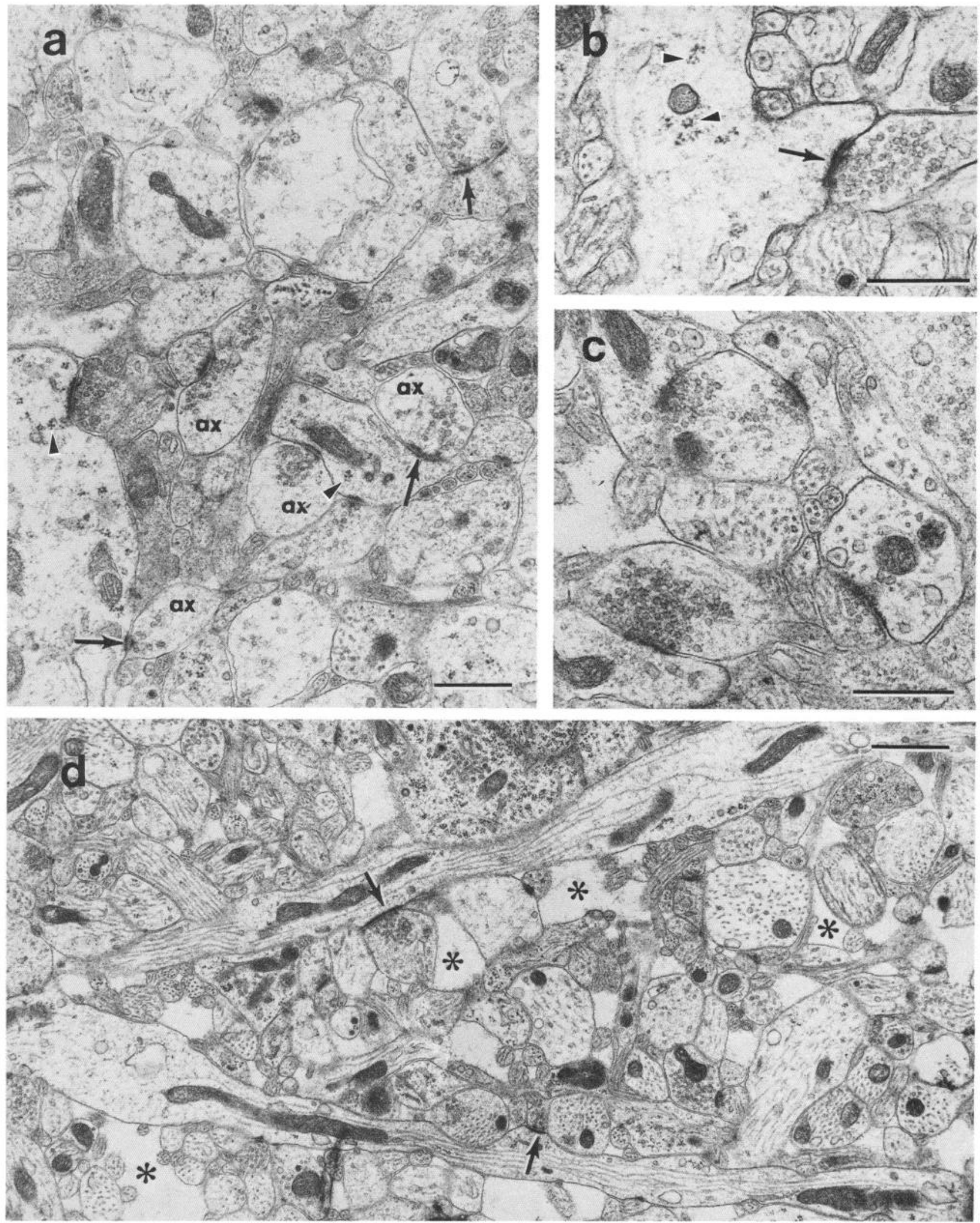

Figure 9. Ultrastructural features of the 2-week-old transplant. $a$, Transplant in a kainate-lesioned caudate nucleus. $b-d$, Taken from transplant neuropil in sham-lesioned neostriatum. $a$, Immature aspects of the graft are evident in this region and include the overall empty appearance of the profiles, scarcity of vesicles within axon terminals $(a x)$, immature synapses (arrows), and ribosome rosettes in dendrites (arrowheads). $b$, Dendrite with a mature asymmetric axospinous synapse (arrow) shows some evidence of active growth by the presence of numerous polyribosomes (arrowheads). $c$, Group of profiles forming synaptic contacts found adjacent to an area of immature neuropil. $d$, Two smooth-surfaced dendrites in a region of immature 2-week-old transplant neuropil. Note the large extracellular spaces (asterisks) and the asymmetric synapse that occurs on each dendrite (arrows). Scale bars: $a-c, 0.5 \mu \mathrm{m} ; d, 1 \mu \mathrm{m}$. 


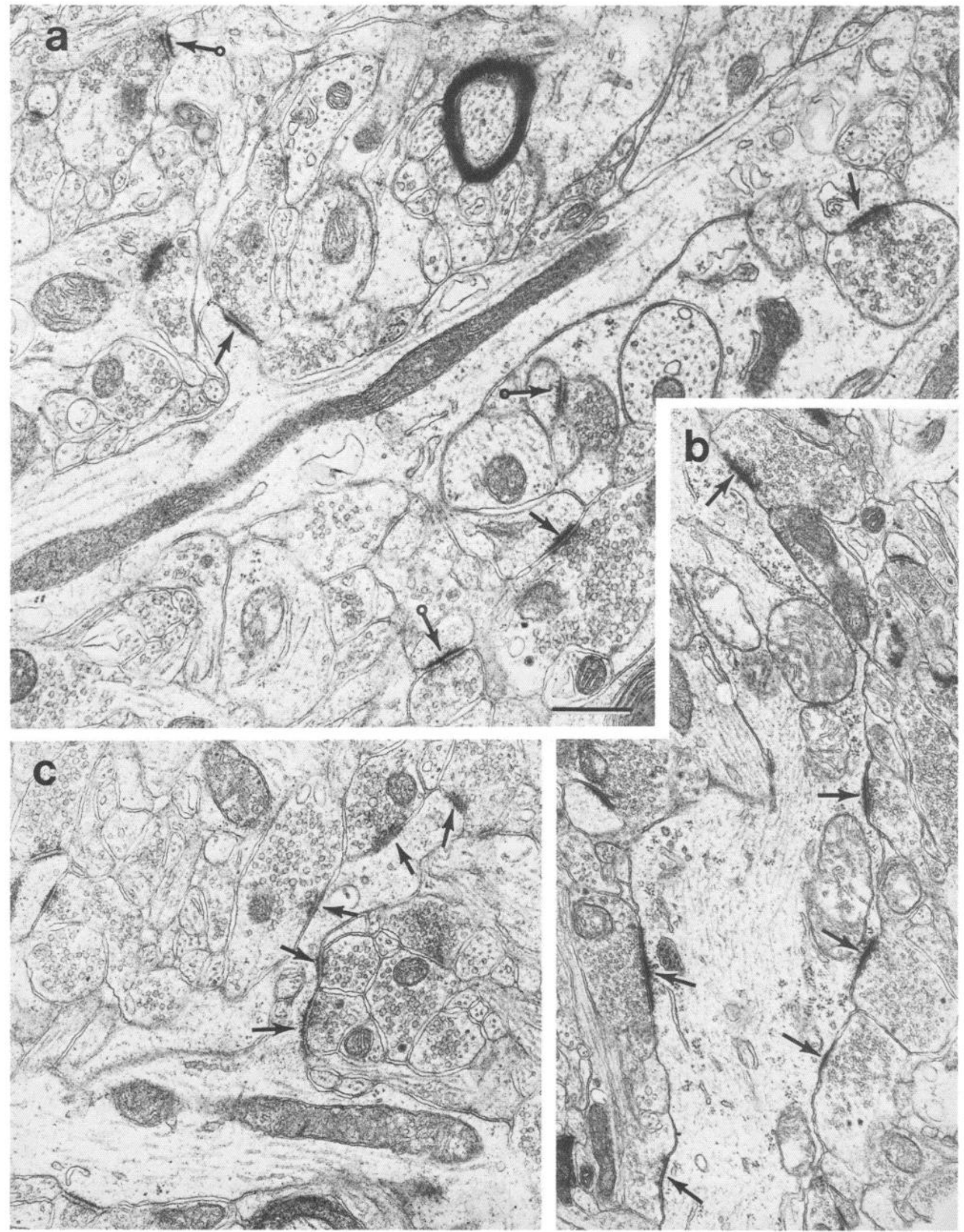

Figure 10. Ultrastructural features of the 5-6 week transplant. Examples are taken from transplants that developed in sham-lesioned caudate nucleus. $a$, A dendrite with 3 emerging spines, all of which receive asymmetric synapses (arrows) from axon terminals with round vesicles. Other axospinous synapses appear within the neuropil (ringed arrows). This region of transplant neuropil looks very similar to host neostriatum. $b$, Largediameter dendrite surrounded by axon terminals, many of which form synaptic contacts (arrows). $c$, Dendrite with long spinelike process surrounded by axons forming synapses (arrows). This type of synaptic interaction is characteristic of the globus pallidus (see DiFiglia et al., 1982, Fig. 17). Scale bar: $a-c, 0.5 \mu \mathrm{m}$. 

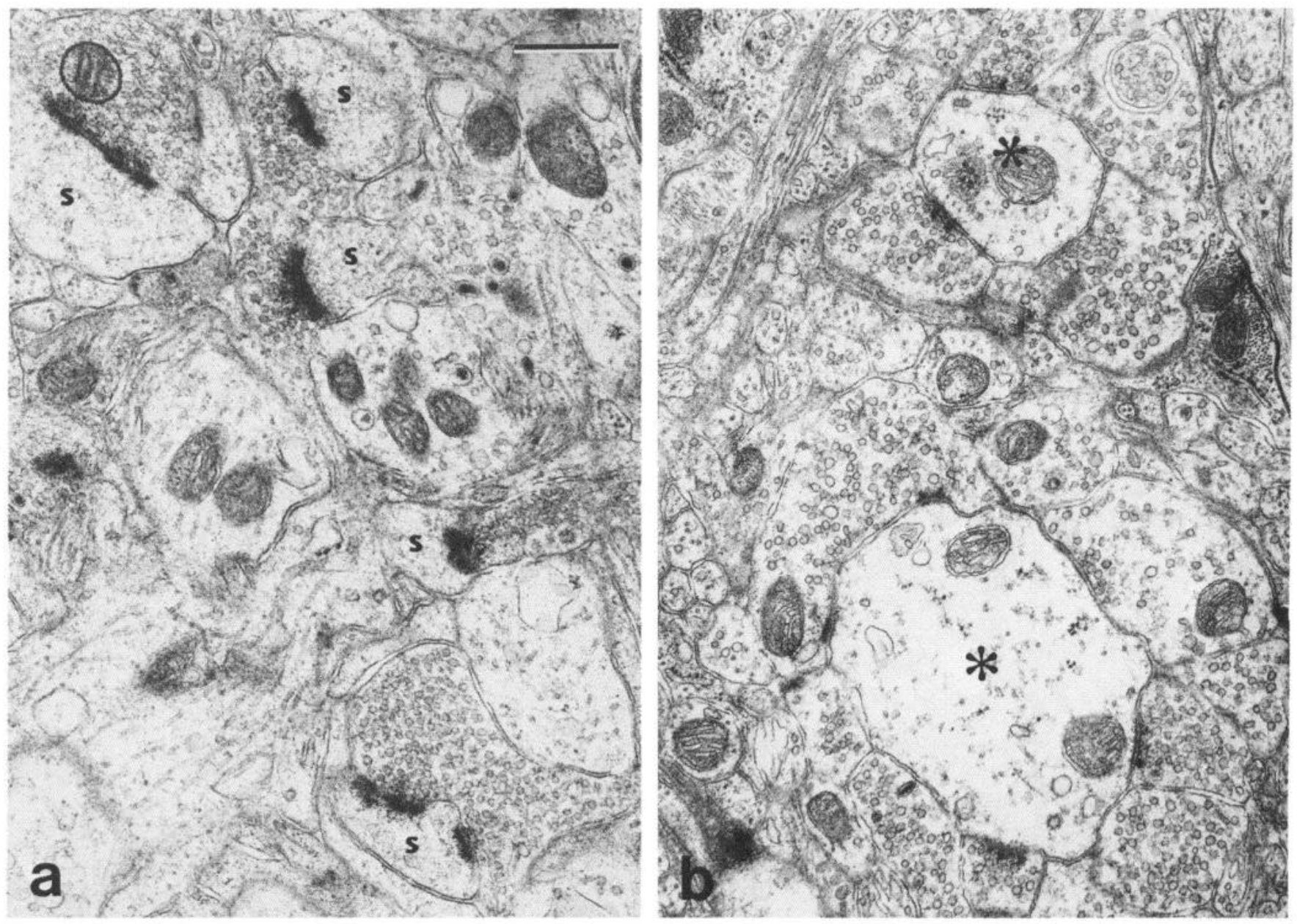

Figure 11. Ultrastructure of the 12 week transplant neuropil. $a, b$, Taken from adjacent areas of neuropil in the same ultrathin section of a transplant in a sham-lesioned host. $a$, Region of neuropil with numerous axons which form synapses with spines $(s)$. $b$, Cross sections of 2 dendrites (asterisks) ensheathed by axons. Scale bar, $0.5 \mu \mathrm{m}$.

$(0.5 \mu \mathrm{m})$ sparsely filled with round and ovoid vesicles (Figs. $12 e$, 13c), medium-sized boutons sparsely filled with pleomorphic vesicles (Fig. 12f), medium-sized (1-1.5 $\mu \mathrm{m})$ axon terminals with pleomorphic vesicles and numerous mitochondria (Fig. $13 b$ ), and medium to large ( $>2 \mu \mathrm{m}$ ) boutons with mostly round clear vesicles and numerous dense-core vesicles (Fig. 13d).

Density of synapses. The type of treatment to host caudate (kainic acid or saline) did not significantly affect the density of synapses in the implants (Fig. 14). Synaptic density in the transplanted tissue appeared to change significantly with the age of the graft (2-way ANOVA: $F(3,16)=14.48, p<0.0001)$, was significantly lower in the 2-week-old implants than in the older grafts (Duncan's Multiple Range Test: $p<0.05$ ), and was at a maximum level by 5-6 weeks. Although mean values were slightly lower, synaptic density in the 12-week-old transplants was statistically comparable to that in the 5-6-week-old implant neuropil. In the 44-48 week transplants, the density of synapses dropped significantly (Duncan's Multiple Range Test: $p<0.05$ ) from that of the 5-6 week grafts.

Synaptic density of the 5-6 week transplants was comparable to that of host caudate neuropil and was significantly lower (1way ANOVA: $F(4,26)=19.94, p<0.0001$; Duncan's Multiple Range Test: $p<0.05$ ) than host neuropil in the 2, 12, and 4448 week transplants.
Types of synapses. The frequency of axodendritic synapses in the implants was not significantly affected by the type of lesion made in host caudate nucleus (Fig. 15). The age of the graft also had no effect on the proportion of axodendritic synapses, with the exception of the 44-48 week grafts, which, on post hoc analysis (Duncan's Multiple Range Test: $p<0.05$ ) had a mean percentage significantly larger than that of the 5-6-and 12-weekold transplants. The proportion of axodendritic synapses was not significantly higher in the 2-week-old implants than in the 5-6 week group. The frequency of axodendritic synapses in the transplants of all ages was signficantly larger (means, $28-58 \%$; 1-way ANOVA: $F(4,26)=7.65, p<0.001)$ than in host neostriatum (mean, $20 \%$ ).

The frequency of asymmetric axodendritic synapses in the striatal implants (Table 2A) did not vary signficantly with host treatment or with the age of the implants. However, asymmetric axodendritic synapses were significantly higher (1-way ANOVA: $F(4,26)=8.86, p<0.0001$; Duncan's Multiple Range Test: $p<0.05)$ in frequency in the grafts than in host tissue. The frequency of asymmetric axospinous synapses in the grafts (Table $2 \mathrm{~B}$ ) did not differ significantly from that in host caudate neuropil.

Lengths of synaptic contacts. A small but significant interaction effect (age $\times$ treatment: $F(3,16)=3.43, p<0.05$; Duncan's 

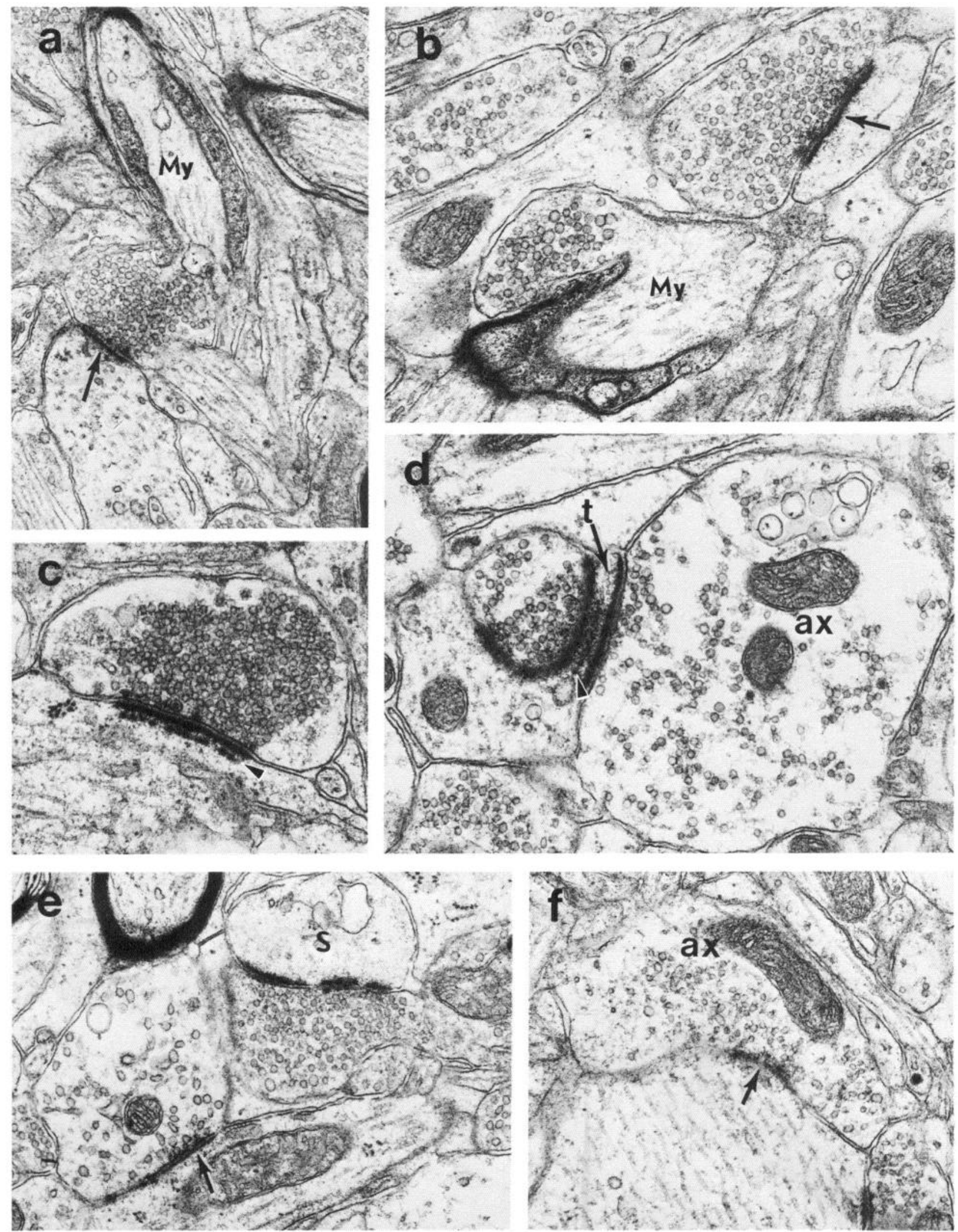

Figure 12. a, A myelinated axon ( $M y)$ gives rise to a bouton with round vesicles and forms an asymmetric synapse (arrow) with dendrite. Taken from a 6 week transplant in sham-lesioned host. $b$, Bouton with round vesicles is similar to the axon terminal shown in $a$ and forms asymmetric synapse (arrow) with a dendritic spine. Another bouton, also with round vesicles, arises from a small-diameter myelinated axon ( $M y)$. Boutons of this type, which form asymmetric synapses, were the most frequently observed in the transplant neuropil and are comparable in size and appearance to axons observed in the neostriatum. Taken from 12 week transplant in a sham-lesioned host. $c$, Axon terminal densely packed with round vesicles forms an asymmetric junction with prominent postsynaptic dense bodies (arrowhead). Subjunctional dense bodies have been observed more 


\begin{tabular}{|c|c|c|c|c|c|}
\hline & 2 week & 5-6 week & 12 week & 44-48 week & Host \\
\hline \multicolumn{6}{|l|}{ A. Dendrites } \\
\hline Sham lesion & $\begin{array}{l}69.4 \pm 6.5 \\
(n=4)\end{array}$ & $\begin{array}{l}61.2 \pm 15.6 \\
(n=3)\end{array}$ & $\begin{array}{l}75.2 \pm 2.0 \\
(n=3)\end{array}$ & $\begin{array}{l}58.4 \pm 10.8 \\
(n=2)\end{array}$ & $\begin{array}{l}38.4 \pm 15.5 \\
(n=7)\end{array}$ \\
\hline $\begin{array}{l}\text { Kainic acid } \\
\text { lesion }\end{array}$ & $\begin{array}{l}66.5 \pm 8.3 \\
(n=4)\end{array}$ & $\begin{array}{l}64.0 \pm 4.5 \\
(n=2)\end{array}$ & $\begin{array}{l}62.9 \pm 6.4 \\
(n=4)\end{array}$ & $\begin{array}{l}68.7 \pm 16.1 \\
(n=2)\end{array}$ & \\
\hline \multicolumn{6}{|l|}{ B. Spines } \\
\hline Sham lesion & $\begin{array}{l}90.1 \pm 4.9 \\
(n=4)\end{array}$ & $\begin{array}{l}93.1 \pm 6.4 \\
(n=3)\end{array}$ & $\begin{array}{l}92.9 \pm 6.4 \\
(n=3)\end{array}$ & $\begin{array}{l}93.0 \pm 11.2 \\
(n=2)\end{array}$ & $\begin{array}{l}91.5 \pm 3.6 \\
(n=7)\end{array}$ \\
\hline $\begin{array}{l}\text { Kainic acid } \\
\text { lesion }\end{array}$ & $\begin{array}{l}88.8 \pm 7.7 \\
(n=4)\end{array}$ & $\begin{array}{l}91.7 \pm 4.4 \\
(n=2)\end{array}$ & $\begin{array}{l}94.8 \pm 10.5 \\
(n=4)\end{array}$ & $\begin{array}{l}94.3 \pm 0.6 \\
(n=2)\end{array}$ & \\
\hline
\end{tabular}

ANOVA with post hoc Duncan's Multiple Range Test showed that for dendrites (A) grafts of all ages were significantly different from host $(p<0.05)$. $n$, Number of grafts.

Multiple Range Test: $p<0.05)$ showed that the 2 and 12 week transplants in host animals treated with kainic acid had significantly longer synaptic junctions on their dendrites than those receiving sham lesions (Table 3 , column 2). By contrast, the lengths of synaptic junctions on spines did not differ significantly by age or host treatment (Table 3, column 3). The mean lengths of axodendritic and axospinous synapses in the implants did not differ significantly from those of host caudate tissue.

\section{Discussion}

The results of this study showed that fetal day 17-18 striatal neurons can develop a complex ultrastructural organization within 5-12 weeks following implantation into a sham-lesioned or kainic acid-lesioned adult host caudate nucleus. This organization included the development of at least 6 morphological cell types and 8 types of axon terminals that formed asymmetric and symmetric synapses with a diverse group of postsynaptic targets. Quantitative methods further revealed that, following implantation into the caudate nucleus, fetal striatal cells (1) showed significant changes in synaptic organization between 2 and 48 weeks following implantation, (2) exhibited both similarities to and differences in neuronal organization from the neostriatum, and (3) differentiated as well in host neostriatum that was previously lesioned with kainic acid as in host that was injected with vehicle only.

Striatal grafts at the light-microscopic level differed histologically from the surrounding host caudate nucleus. Many neurons within the transplants were found in clusters, and medium-sized somata had significantly larger cross-sectional areas. Grafted striatal neurons within clusters (Walker et al., 1987) and with "somewhat larger" somata (McGeer et al., 1984) have also been observed in other studies of striatal grafts. The absence of bundles of myelinated axons in striatal transplants as compared in host caudate has also been observed in striatal grafts originating from fetuses younger than those used in this study (Isacson et al., 1985). Differences between striatal graft and adult host caudate have also been noted in the distribution of AChE activity (Sanberg et al., 1986; Walker et al., 1987) and catecholamine fluorescence (Pritzel et al., 1986).

Some features that characterized the developing striatal grafts have been observed in ultrastructural studies of the early postnatal neostriatum (Tennyson et al., 1972; Tanaka and Alexander, 1978; DiFiglia et al., 1979, 1980a). As in the grafts, growth cones, immature synapses, and numerous cisterns and ribosomes within spiny dendrites have been observed in the developing caudate nucleus. Similarly, the neuronal degeneration observed in the striatal transplants has been described in the early postnatal neostriatum (Mensah, 1978; DiFiglia et al., 1980a). Cell death has been thought to result from a process of neuronal remodeling occurring in the course of normal development of the nervous system (Cowan et al., 1973). $\Lambda$ s was also seen in the early postnatal caudate nucleus (Tennyson et al., 1972; Hattori and McGeer, 1973; DiFiglia et al., 1979, 1980a), synaptic density in the implants increased, with a significant change occurring between 2 and 6 weeks following implantation. The decline in the density of synapses that was observed in the older transplants has not been described in studies of the neostriatum and also suggests that transplants may continue to undergo marked changes in synaptic organization over relatively long periods of time. Other evidence in this study indicating long-term changes in the transplants includes a significant increase in the older grafts in the occurrence of large neurons and in the proportion of axodendritic synapses.

The ultrastructure of fetal striatal transplants showed a greater maturation than that observed for striatal neurons in vitro (Panula et al., 1979; Whetsell et al., 1979). The 6 types of neurons found in the grafts were more differentiated and had more axosomatic synapses than did the 4 neuronal types described in

frequently in association with asymmetric synapses in the globus pallidus (DiFiglia et al., 1982, Fig. 26). Taken from a 48 week transplant in shamlesioned caudate nucleus. $d$, A large bouton $(a x)$ contacts a thornlike dendritic protrusion $(t)$, where it forms an asymmetric synapse with prominent postjunctional bodies (arrowhead). Synapses of this type have been observed in the globus pallidus (DiFiglia et al., 1982, Fig. 16). e, Bouton with round vesicles forms an asymmetric synapse with spine $(s)$ and is adjacent to another terminal with pleomorphic vesicles, which makes a symmetric synapse with a dendrite at arrow. Taken from a 12 week transplant in sham-lesioned host caudate nucleus. $f$, A medium-sized bouton $(a x)$ sparsely filled with small pleomorphic vesicles forms a synaptic contact (arrow) with a large dendrite. Taken from 12 week transplant in a kainate-lesioned host caudate nucleus. Scale bar, $0.5 \mu \mathrm{m}$. 

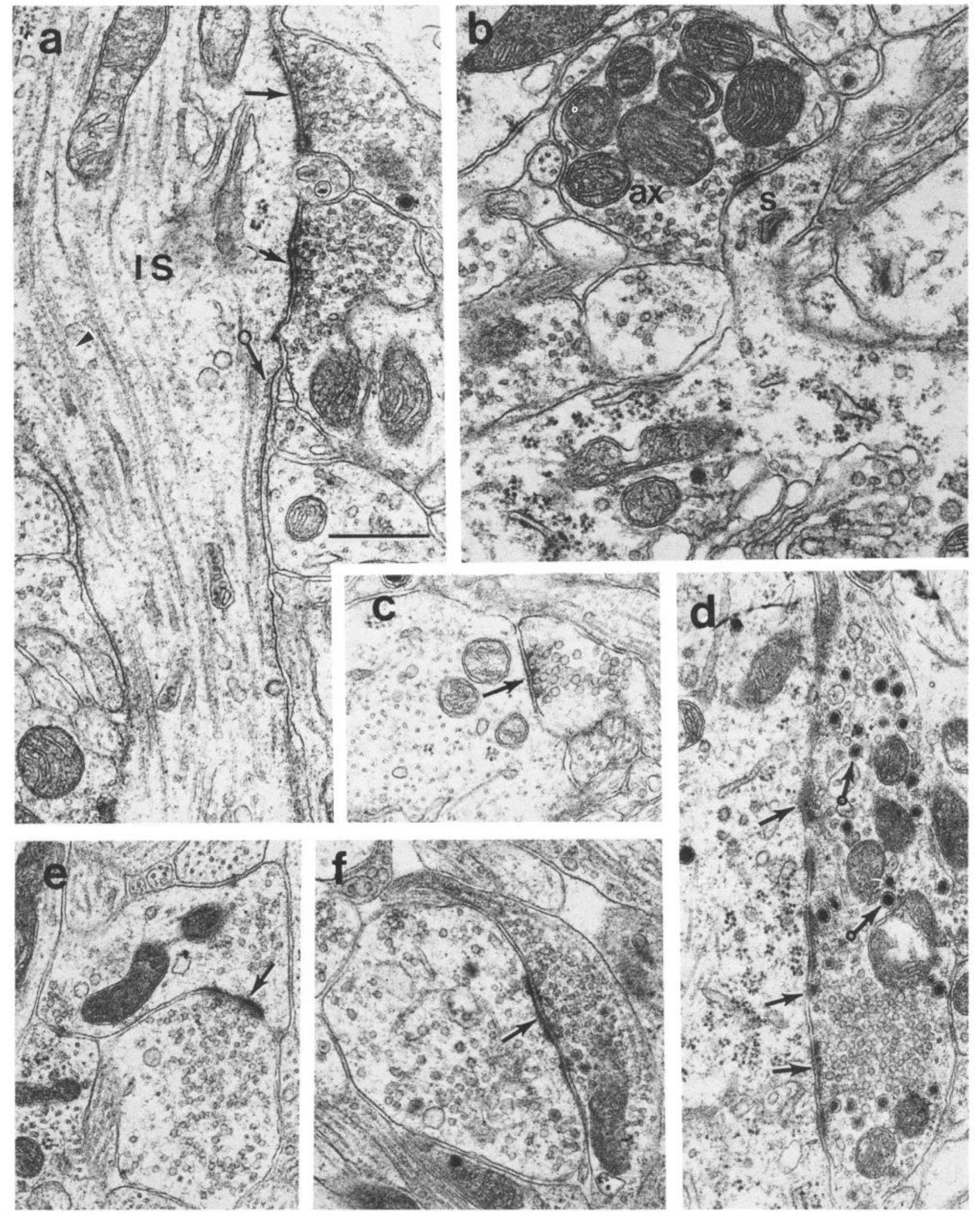

Figure 13. a, Two small boutons filled with pleomorphic vesicles (including flattened ones) synapse at arrows with an axon initial segment (IS). Note the undercoating (ringed arrow) and fasciculation of microtubules (arrowhead) typical of axon initial segments. Taken from a 6 week transplant in a sham-lesioned host caudate nucleus. $b$, A bouton $(a x)$ with numerous mitochondria and pleomorphic vesicles makes a symmetric synapse with somatic spine $(s)$. Taken from a 48 week transplant in a sham-lesioned host. $c$, A symmetric synapse (arrow) is formed by a bouton with round to ovoid vesicles. Taken from a 6 week implant in sham-lesioned host. $d$, A bouton with clear round vesicles and numerous large densecore vesicles (ringed arrows) forms multiple synaptic contacts (arrows) with a neuron in a 12 week graft in sham-lesioned host. $e$, $f$, Examples of synaptic contacts between vesicle-containing profiles found in a 12 week transplant in a sham-lesioned host. The synapses formed in both examples appear asymmetric (arrows). Synapses between vesicle-containing profiles have not been observed in the neostriatum, but have been found in the globus pallidus, where one of the participating profiles has been shown to be a dendrite (see DiFiglia et al., 1982, Figs. 28-36). Scale bar, $0.5 \mu \mathrm{m}$. 


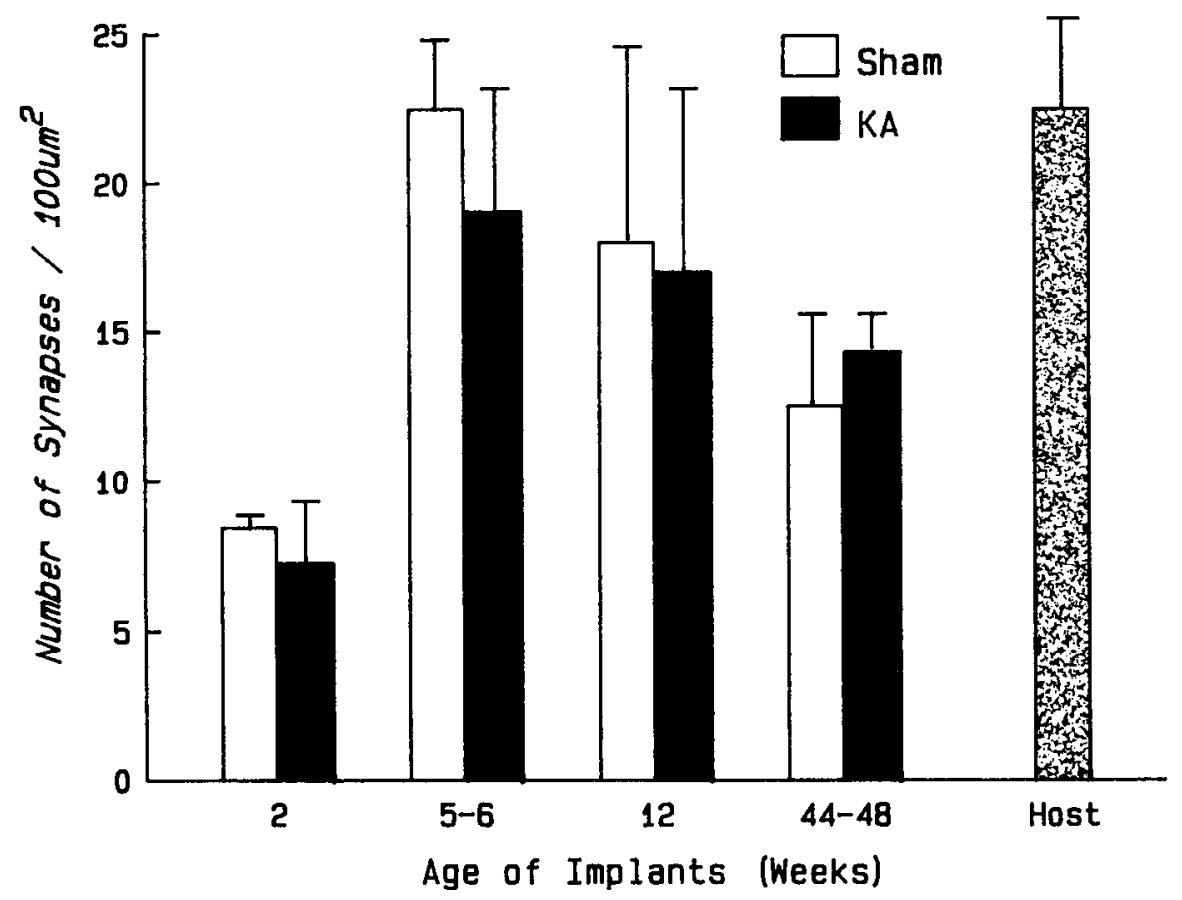

Figure 14. Density of synapses (expressed as number of synapses per 100 $\mu \mathrm{m}^{2}$ of neuropil) for each age and treat. ment condition and in host caudate nucleus $(n=7)$. The number of grafts examined in each age/treatment group is the same as in Table 1 (except for 5-6 weeks/kainic acid, where $n=2$ ). ANOVA with post hoc Duncan's Multiple Range Test showed 2 week to be different from 5-6 and 44-48 week groups $(p<0.05)$, and 2,12 , and $44-48$ week groups different from host $(p<0.05)$. $K A$, kainic acid. dissociated striatal cultures (Panula et al., 1979). The most striking difference between grafted and cultured striatal neurons was the presence of numerous axospinous asymmetric synapses in the transplants and their absence in both dissociated (Panula et al., 1979) and organotypic (Whetsell et al., 1979) striatal cultures. One possible reason for the lack of asymmetric axospinous synapses in culture is the absence of appropriate striatal afferents to stimulate the development of spines and their synapses. In fact, when organotypic striatal cultures were grown in the presence of a cortical explant, they developed both spines and axospinous synapses (Whetsell et al., 1979).

Measures of synaptic density confirmed the remarkable degree of neuronal differentiation apparent within striatal grafts. The density of synapses in the 5-6 week transplants was statistically comparable to that in the neostriatum $(93 \%$ of the density of the neostriatum). Compared to the host caudate nucleus, the density of synapses in the 12-week-old grafts was somewhat lower (78\% of neostriatal values) and significantly lower at 2 weeks ( $34 \%$ of the neostriatum) and $44-48$ weeks ( $58.5 \%)$. These results suggest that fetal striatal cells are maximally developed between 5 and 12 weeks following implantation. Regardless of the age of the grafts, however, the lengths of their synaptic junctions (except for axospinous junctions in the 5-6 week transplants) were the same as those in the caudate nucleus. This finding, together with the presence of numerous vesicles in presynaptic axons in the grafts, suggests that synaptic activity at individual synapses may be similar to that in the neostriatal neuropil.

Our ultrastructural findings support previous observations, using Golgi methods, that neurons with numerous spine-laden dendrites are present in striatal grafts (McAlliister et al., 1985). In the neostriatum, the majority of synaptic inputs to spines, which constitute more than $80 \%$ of all synapses (Pasik et al., 1976), are of extrinsic origin and form asymmetric synapses (Kemp and Powell, 1971; Haltori et al., 1973; Chung et al., 1977; Hassler et al., 1978; Pasik et al., 1979). It seems likely that some of the axons that made asymmetric contact with spines in the transplants arose from extrinsic sources. There is evidence based on retrograde labeling with HRP for the existence of afferent inputs to striatal grafts, largely from the substantia nigra and, to a lesser extent, from the thalamus and cortex (Pritzel et al., 1986). Histochemical fluorescence of catecholamine fibers in striatal transplants supports a possible dopaminergic innervation from the substantia nigra (McGeer et al., 1984; Pritzel et al., 1986), and dopamine receptors have been found on transplanted striatal cells (Deckel et al., 1986b). Our observation that myelinated fibers appeared to enter the transplants from the cercbral cortex is consistent with evidence for a cortical afferent input (Pritzel et al., 1986). Our results also suggested that the axons of intrinsic host caudate neurons do not contribute significantly to the synaptic organization of the

Table 3. Length of synapses (mean in $\mathrm{mm}^{2} \pm \mathrm{SD}$ )

\begin{tabular}{lll} 
& Axodendritic & Axospinous \\
\hline 2 week & & \\
$\quad$ Sham lesion & $0.30 \pm 0.03(n=4)$ & $0.27 \pm 0.02(n=4)$ \\
$\quad$ Kainic acid lesion & $0.35 \pm 0.02(n=4)$ & $0.28+0.03(n=4)$ \\
5-6 week & & \\
$\quad$ Sham lesion & $0.29 \pm 0.03(n=3)$ & $0.27 \pm 0.01(n=3)$ \\
$\quad$ Kainic acid lesion & $0.32 \pm 0.00(n=2)$ & $0.26 \pm 0.02(n=2)$ \\
12 week & & \\
$\quad$ Sham lesion & $0.32 \pm 0.02(n=3)$ & $0.31 \pm 0.03(n=3)$ \\
$\quad$ Kainic acid lesion & $0.36 \pm 0.04(n=4)$ & $0.27 \pm 0.03(n=4)$ \\
44-48 week & & \\
$\quad$ Sham lesion & $0.35 \pm 0.01(n=2)$ & $0.35 \pm 0.00(n=2)$ \\
$\quad$ Kainic acid lesion & $0.30 \pm 0.02(n=2)$ & $0.27 \pm 0.00(n=2)$ \\
Host & $0.31 \pm 0.05(n=7)$ & $0.31 \pm 0.03(n=7)$
\end{tabular}

ANOVA with post hoc Duncan's Multiple Range Test showed for axodendritic synapses a significant age $\times$ treatment interaction $(p<0.05)$ with 2 and 12 week grafts in kainic acid host having longer synaptic junctions. $n$, Number of grafts. 
Figure 15. Frequency of axodendritic synapses (expressed as percentage of total axospinous and axodendritic synapses) in the neuropil of grafts at different ages/treatments and in the host ncostriatum. The number of grafts cxamined in each age/treatment group is the same as in Table 1 (except for 5-6 weeks/kainic acid groups, where $n=2$ grafts). ANOVA with post hoc Duncan's Multiple Range Test showed the 44-48 week to be significantly different from 5-6 and 12 week groups $(p<0.05)$, and all age groups to be different from host neostriatum $(p<0.05)$. $K A$, kainic acid.

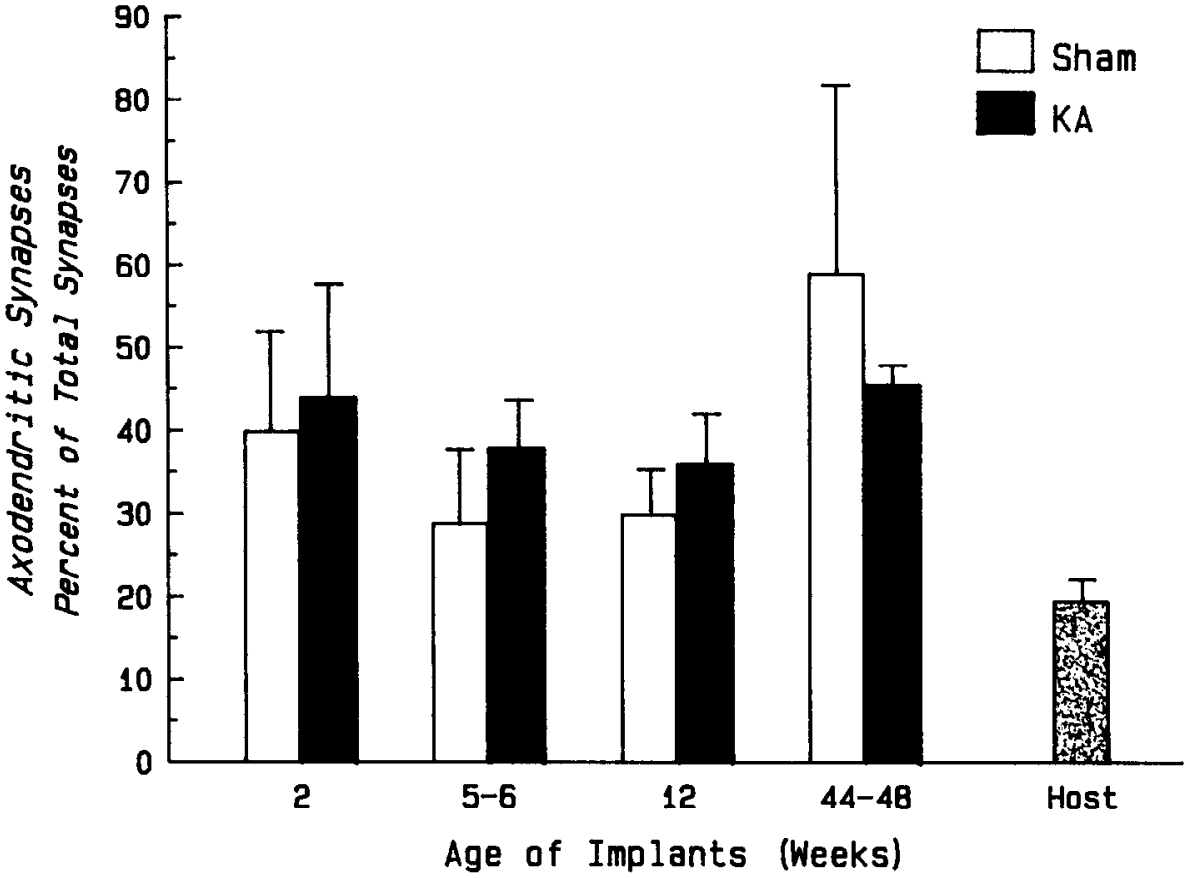

with the same nuclear morphology. On the other hand, the much higher proportion of axodendritic synapses, or, conversely, the lower frequency of axospinous synapses in the grafts, compared to in the neostriatum, could be explained by a higher incidence of aspiny neurons in the grafts. Alternatively, it may be that some spiny neurons in the grafts have fewer spines than neostriatal spiny cells, a possibility that has some support from Golgi studies of striatal grafts (McAllister et al., 1985). The much higher proportion of axodendritic synapses with asymmetric contacts in the grafts (58-75\%) than in the host neuropil (38\%) may also reflect an important functional difference, since asymmetric contacts have been associated with excitatory activity.

Some ultrastructural features of the transplant neuropil, including dendrites and long, spinelike processes ensheathed by synapsing axon terminals, asymmetric synapses with prominent postjunctional bodies, rodlike synapses, and synaptic contacts between vesicle-containing profiles, have been infrequently or rarely, if ever, observed in neostriatal neuropil. Interestingly, all of these features of the grafts are more characteristic of the globus pallidus (Adinolfi, 1969; Kemp and Powell, 1971; Fox et al., 1974; Fox and Rafols, 1976; DiFiglia et al., 1982). Although the globus pallidus has been thought to derive from the embryonic basal plate of the diencephaion, the proximity of the pallidal anlage to the ventricular elevation, specifically the ventral portion of the medial elevation, has raised speculation that pallidal cells could arise from this source (see review and discussion by Smart and Sturrock, 1979). If this is so, then the pallidal-like architecture seen in the transplants may be accounted for in part by the presence of some presumptive pallidal neurons in the fetal tissue used for grafting. A pallidal origin might also explain other features of the grafts that are characteristic of the globus pallidus, such as the prevalence of neurons with indented nuclei and large somal sizes (Adinolfi, 1969; Fox et al., 1974; Fox and Rafols, 1976; DiFiglia et al., 1982). It is of interest that different clusters of "pallidal-like" or "ncostriatal-like" AChE-containing neurons have been described within as in the ncostriatum, and that many neurons with indented nuclei in the grafts may differ functionally from neostriatal cells 
the same striatal grafts by Walker et al. (1987), who have suggested that functional subsets of pallidal-type neurons may be present within striatal grafts.

The morphological maturation observed in striatal transplants in the present study is consistent with behavioral and biochemical evidence for functional changes associated with striatal grafts. With the same methods used in this study to produce caudate lesions and intrastriatal grafts, Deckel et al. (1983, 1986a) and Deckel and Robinson (1987) showed that deficits in reward alternation, locomotion, seizure activity, and some feeding abnormalities induced by kainic acid lesions of the caudate nucleus were partially reversed by fetal striatal transplants in to the lesioned area. In a similar study, rats that received caudate lesions made with ibotenic acid and then fetal striatal grafts showed little or no change in locomotor activity, as compared to lesioned rats that remained hyperactive (Isacson et al., 1984). The caudate nuclei of ibotenate-lesioned and grafted rats also showed significantly higher levels of glutamate decarboxylase and choline acetyltransferase than the caudates of lesioned rats (Isacson et al., 1985). As in the neostriatum, immunohistochemical localization of GABA and enkephalins to mediumsized neurons (Roberts et al., 1987) and histochemical localization of AChE to large neurons (Walker et al., 1987) has been observed in striatal grafts in the chemically lesioned rat caudate nucleus. Kainic acid and ibotenic acid in the neostriatum are known to destroy intrinsic neurons and to spare afferent fibers, and this feature has been used as a model to study the anatomical, biochemical, and behavioral effects of severe neuronal loss in the neostriatum (Coyle et al., 1979; McGeer et al., 1979; Isacson et al., 1985) that is characteristic of Huntington's disease. It has been suggested that fetal striatal transplants may exert their influence on the lesioned host caudate nucleus by direct axonal connections with spared host caudate neurons or by the diffuse release of substances that may act either locally in host tissue or at more distant sites in the brain (Isacson et al., 1984). After anterograde labeling, the axons of grafted neurons have been observed traversing host neuropil (Pritzel et al., 1986).

In summary, the present findings demonstrate that fetal day 17 striatal tissue implanted into adult host neostriatum develops a complex ultrastructural organization that is qualitatively similar whether the host caudate was previously injected with saline (sham condition) or lesioned with kainic acid. The striatal grafts were more differentiated than striatal cells in vitro, appeared mature by 5-6 weeks postimplant, and remained intact up to 48 weeks. The synaptic architecture of the grafts had a neostriatal-like organization to the extent that it contained a high density of synapses onto spines. As in the caudate nucleus, axons that synapsc with spincs in the transplants may arise from extrinsic afferents. The presence in the transplant neuropil of other neuronal and synaptic features that were less characteristic of the neostriatum suggests that some functional properties of the grafts may differ from those of the neostriatum. The interpretation of results in biochemical and behavioral studies of striatal transplants must take into account their unique morphology.

\section{References}

Adinolf, A. M. (1969) The fine structure of ncurons and synapses in the entopeduncular nucleus of the cat. J. Comp. Neurol. 135: 225248.

Björklund, A., R. H. Schmidt, and U. Stenevi (1980) Functional reinnervation of the neostriatum in the adult rat by use of intraparen- chymal grafting of dissociated cell suspensions from the substantia nigra. Cell Tissue Res. 212: 39-45.

Bolam, J. P., P. Somogyi, H. Takagi, I. Fodor, and A. D. Smith (1983) Localization of substance P-like immunoreactivity in neurons and nerve terminals in the neostriatum of the rat: A correlated light and electron miscroscopic study. J. Neurocytol. 12: 325-344.

Bolam, J. P., J. F. Powell, J.-Y. Wu, and A. D. Smith (1985) Glutamate decarboxylase-immunoreactive structures in the rat neostriatum: A correlated light and electron microscopic study including a combination of Golgi impregnation with immunocytochemistry. J. Comp. Neurol. 237: 1-20.

Chung, J. W., R. Hassler, and A. Wagner (1977) Degeneration of two of nine types of synapses in the putamen after centre median coagulation in the cat. Exp. Brain Res. 28: 345-361.

Cowan, W. M. (1973) Neuronal death as a regulative mechanism in the control of cell number in the nervous system. In Development and Aging in the Nervous System, M. Rockstein and M. S. Susman, eds., pp. 19-41, Academic, New York.

Coyle, J. T., M. E. Molliver, and M. J. Kuhar (1978) In situ injection of kainic acid: A new method for selectively lesioning neuronal cell bodies while sparing axons of passage. J. Comp. Neurol. 180: 301324.

Coyle, J. T., E. D. Landon, K. Biziere, and R. Zaczek (1979) Kainic acid neurotoxicity. Insights into the pathophysiology of Huntington's disease. In Advances in Neurology, vol. 23, T. N. Chase, N. S. Wexler, and A. Barbeau, eds., pp. 593-608, Raven, New York.

Das, C. D., B. H. Hallas, and K. G. Das (1980) Transplantation of brain tissue in the brain of rat. I. Growth characteristics of neocortical transplants from embryos of different ages. Am. J. Anat. 158: 135145 .

Deckel, A. W., and R. G. Robinson (1987) Receptor characteristics and behavioral consequences of kainic acid lesions and fetal transplants of the striatum. Annu. N.Y. Acad. Sci. 495: 556-580.

Deckel, A. W., R. G. Robinson, J. T. Coyle, and P. R. Sanberg (1983) Reversal of long-term locomotor abnormalities in the kainic acid model of Huntington's disease by day 18 fetal striatal implants. Eur. J. Pharmacol. 93: 287-288.

Deckel, A. W., T. H. Moran, J. T. Coyle, P. R. Sanberg, and R. G. Robinson (1986a) Anatomical predictors of behavioral recovery following fetal striatal transplants. Brain Res. 365: 249-258.

Deckel, A. W., T. V. Moran, and R. G. Robinson (1986b) Behavioral recovery following kainic acid lesions and fetal implants of the striatum occurs independently of dopaminergic mechanisms. Brain Res. 363: 383-385.

DiFiglia, M., and N. Aronin (1982) Ultrastructural features of immunoreactive somatostatin neurons in the rat caudate nucleus. J. Neurosci. 2: 1267-1274.

DiFiglia, M., T. Pasik, and P. Pasik (1979) Developmental aspects of neostriatal organization in monkeys. Appl. Neurophysiol. 42: 81-83.

DiFiglia, M., P. Pasik, and T. Pasik (1980a) Early postnatal development of the monkey neostriatum: A Golgi and ultrastructural study. J. Comp. Neurol. 190: 303-331.

DiFiglia, M., T. Pasik, and P. Pasik (1980b) Ultrastructure of Golgiimpregnated and gold-toned spiny and aspiny neurons in the monkey neostriatum. J. Neurocytol. 9: 471-492.

DiFiglia, M., P. Pasik, and T. Pasik (1982) A Golgi and ultrastructural study of the monkey globus pallidus. J. Comp. Neurol. 212: 53-75.

DiFiglia, M., L. Schiff, and A. W. Deckel (1985) Synaptic organization of fetal striatal transplants in the normal and kainate lesioned rat caudate nucleus. Soc. Neurosci. Abstr. 11: 365.

DiMova, R., J. Vuillet, and R. Seite (1980) Study of the rat neostriatum using a combined Golgi-electron microscopic technique and serial sections. Neuroscience 5: 1581-1596.

Dunnett, S. B., W. C. Low, S. D. Iversen, U. Stenevi, and A. Björklund (1982) Septal transplants restore maze learning in rats with fornixfimbria lesions. Brain Res. 251: 335-348.

Fox, C. A., and J. A. Rafols (1976) The striatal efferents in the globus pallidus and in the substantia nigra. In The Basal Ganglia, M. D. Yahr, ed., pp. 37-55, Raven, New York.

Fox, C. A., A. N. Andrade, I. J. LuQui, and J. A. Rafols (1974) The primate globus pallidus: A Golgi and electron microscopic study. J. Hirnforsch. 15: 75-93.

Gage, F. H., S. B. Dunnett, A. Björklund, and U. Stenevi (1983) Aged rats: Recovery of motor coordination impairments by intrastriatal nigral grafts. Science 219: 416-418. 
Gibson, M. J., D. T. Krieger, M. J. Perlow, T. F. Davies, E. A. Zimmerman, M. Ferin, and H. M. Charlton (1983) Brain tissue grafts in the central nervous system: Reversal of hypogonadism. J. Exp. Physiol. 68: 475-482.

Graveland, G. A., and M. DiFiglia (1985) The frequency and distribution of medium-sized neurons with indented nuclei in the primate and rodent neostriatum. Brain Res. 327: 307-311.

Hassler, R., J. W. Chung, U. Rinne, and A. Wagner (1978) Selective degeneration of two out of nine types of synapses in cat caudate nucleus after cortical lesions. Exp. Brain Res. 31: 67-80.

Hattori, T., H. C. Fiber, P. L. McGeer, and L. Maler (1973) Analysis of the fine structure of the dopaminergic nigrostriatal projection by electron microscopic autoradiography. Exp. Neurol. 41: 599-611.

Isacson, O., P. Brundin, P. A. T. Kelly, F. H. Gage, and A. Björklund (1984) Functional neuronal replacement by grafted striatal neurones in the ibotenic acid-lesioned rat striatum. Nature 311: 458-460.

Isacson, O., P. Brundin, F. H. Gage, and A. Björklund (1985) Neural grafting in a rat model of Huntington's disease: Progressive neurochemical changes after neostriatal ibotenate lesions and striatal tissue grafting. Neuroscience 16: 799-818.

Isacson, O., S. B. Dunnett, and A. Björklund (1986) Graft-induced behavioral recovery in an animal model of Huntington's disease. Proc. Natl. Acad. Sci. USA 83: 2728-2732

Kemp, J. M., and T. P. S. Powell (1971) The site of termination of afferent fibers in the caudate nucleus. Phil. Trans. R. Soc. Lond. [Biol.] 262: 413-427.

Kluver, H., and E. Barrera (1953) A method for the combined staining of cells and fibers in the nervous sytem. J. Neuropathol. Exp. Neurol. 12: $400-403$.

Lund, R. J., and S. D. Ilauschka (1976) Transplanted neural tissue develops connections with host brain. Science 193: 582-584.

McAllister, J. P., P. D. Walker, M. C. Zemanick, A. B. Weber, L. I. Kaplan, and M. A. Reynolds (1985) Morphology of embryonic neostriatal cell suspensions transplanted into adult neostriatum. Dev. Brain Res. 23: 282-286.

McGeer, E. G., P. L. McGeer, T. Hattori, and S. R. Vincent (1979) Kainic acid neurotoxicity and Huntington's disease. In Advances in Neurology, vol. 23, T. N. Chase, N. S. Wexler, and A. Barbeau, eds. pp. 577-592, Raven, New York.

McGeer, P. L., H. Kimura, and E. G. McGeer (1984) Transplantation of newborn brain tissue into adult kainic-acid-lesioned neostriatum. In Neural Transplants, Development and Function, J. R. Sladek, Jr. and D. M. Gash, eds., pp. 361-371, Plenum, New York.

Mensah, P. (1978) Neuronal cell death in the neostriatum of perinatal mouse. Anat. Rec. 190: 479-480.

Panula, P., L. Rechardt, and H. Hervonen (1979) Ultrastructure of cultured rat neostriatum. Neuroscience 4: 1441-1452.

Pasik, P., T. Pasik, and M. DiFiglia (1976) Quantitative aspects of neuronal organization in the neostriatum of the macaque monkey. In
The Basal Ganglia, M. D. Yahr, ed., pp. 55-90, Raven, New York. Pasik, P., T. Pasik, and M. DiFiglia (1979) The internal organization of the neostriatum in mammals. In The Neostriatum, I. Divac and G. E. Oberg, eds., pp. 5-36, Pergamon, Oxford, UK.

Pellegrino, L. J., A. S. Pellegrino, and A. J. Cushman (1979) A Stereotaxic Atlas of the Rat Brain, Plenum, New York.

Pritzel, M., O. Isacson, P. Brundin, L. Wiklund, and A. Björklund (1986) Afferent and efferent connections of striatal grafts implanted into the ibotenic acid lesioned neostriatum in adult rats. Exp. Brain Res. 65 : 112-126.

Roberts, R. C., A. W. Deckel, and M. DiFiglia (1987) Fetal striatal grafts in the lesioned adult rat caudate nucleus contain immunoreactive GABA and enkephalin neurons and NADPH-diaphorase positive cells. Soc. Neurosci. Abstr. 13: 1360.

Sanberg, P. R., M. A. Henault, and A. W. Deckel (1986) Locomotor hyperactivity: Effects of multiple striatal transplants in an animal model of Huntington's Disease. Pharmacol. Biochem. Behav. 25. 297-300.

Schmidt, R. H., A. Björklund, and U. Stenevi (1981) Intracerebral grafting of dissociated CNS tissue suspensions: A new approach for neuronal transplantation to deep brain sites. Brain Res. 218: $347-$ 356.

Smart, I. H. M., and R. R. Sturrock (1979) Ontogeny of the neostriatum. In The Neostriatum. I. Divac and R. G. E. Oherg, eds., pp. 127146, Pergamon, Oxford, UK.

Takagi, H., P. Somogyi, J. Somogyi, and A. D. Smith (1983) Fine structural studies on a type of somatostatin-immunoreactive neuron and its synaptic connections in the rat neostriatum: A correlated light and electron microscopic study. J. Comp. Neurol. 214: 1-16.

Tanaka, D., Jr., and B. Alexander (1978) Golgi and electron microscopic evidence for growth cones in the caudate nucleus of the neonatal dog. Exp. Neurol. 60: 614-623.

Tennyson, V. M., R. E. Barrett, G. Cohen, L. Cote, R. Heikkila, and C. Mytilineou (1972) The developing neostriatum of the rabbit: Correlations of fluorescence histochemistry, electron microscopy, endogenous dopamine levels and ${ }^{3} \mathrm{H}$ dopamine uptake. Brain Res. 46. 251-285.

Vincent, S. R., and O. Johansson (1983) Striatal neurons containing both somatostatin and avian pancreatic polypeptide (APP)-like immunoreactivities and NADPH-diaphorase activity: A light and electron microscopic study. J. Comp. Neurol. 217: 264-270.

Walker, P. D., G. I. Chovanes, and J. P. McAllister II (1987) Identification of acetylcholinesterase-reactive neurons and neuropil in neostriatal transplants. J. Comp. Neurol. 259: 1-12.

Whetsell, W. O., M. S. Ecob-Johnston, and W. J. Nicklas (1979) Studies of kainate-induced caudate lesions in organotypic tissue culture. Adv. Neurol. 23: 645-654.

Zar, J. H. (1974) Biostatistical Analysis, pp. 151-155, Prentice-Hall, Englewood Cliffs, NJ. 